\title{
Recent advances in cellulose-based membranes for their sensing applications
}

\author{
Jiang Fan $\cdot$ Sufeng Zhang $\cdot$ Fei Li $\cdot$ Yonglin Yang $\cdot$ Min Du
}

Received: 14 May 2020/Accepted: 7 September 2020/Published online: 11 September 2020

(C) Springer Nature B.V. 2020

\begin{abstract}
In recent years, sensing applications have played a very important role in various fields. As a novel natural material, cellulose-based membranes with many merits can be served as all kinds of sensors. This review summarizes the recent progress of cellulose membranes as sensors, mainly focusing on their preparation processes and sensing properties. In addition, the opportunities and challenges of cellulose membrane-based sensors are also prospected. This review provides some references for the design of cellulose membrane materials for sensing applications in the future.
\end{abstract}

\section{Graphic abstract}

J. Fan $\cdot$ S. Zhang $(\bowtie) \cdot$ M. Du

Shaanxi Provincial Key Laboratory of Papermaking

Technology and Specialty Paper Development, National

Demonstration Center for Experimental Light Chemistry

Engineering Education, Key Laboratory of Paper Based

Functional Materials of China National Light Industry,

Shaanxi University of Science and Technology,

Xi'an 710021, People's Republic of China

e-mail: zhangsufeng@sust.edu.cn

\section{F. Li}

The Second Kindergarten, Economic and Technological Development Zone, Xi'an 710021, People's Republic of China

\section{Y. Yang}

School of Environmental Science and Engineering,

Shaanxi University of Science and Technology,

Xi' an 710021, People's Republic of China

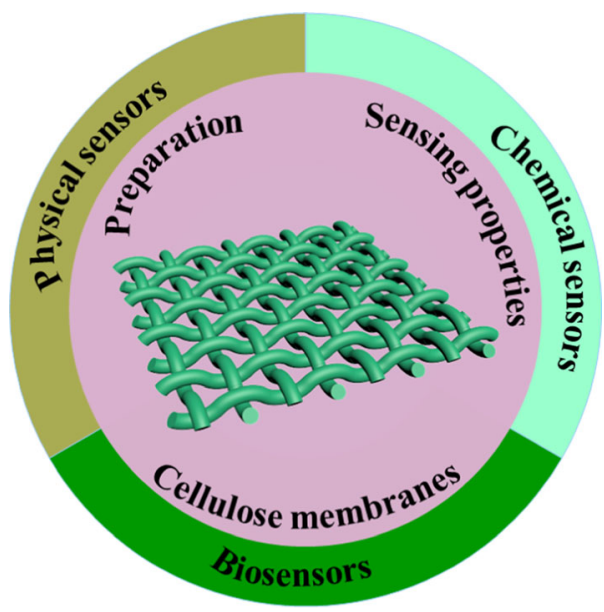

Keywords Cellulose membranes - Sensing · Preparation · Properties

\section{Introduction}

Sensors are widely used in various areas of social development and human life, such as industrial production, agricultural planting, environmental detection and disease diagnosis (Ghoneim et al. 2019). According to the changes of environmental factors, sensors can be divided into three categories: 
physical sensors that respond to pressure/strain, temperature and humidity; chemical sensors that respond to metal cations, non-metal ions, $\mathrm{pH}$, gas/vapor and toxic organic compounds; and biosensors that respond to biomolecules and pathogens (Dai et al. 2020; Zhang et al. 2020; Fan et al. 2020a, b). At present, although the traditional instrument analysis methods have the merits of sensitivity and professionalism, they still exhibit some drawbacks: expensive instruments, complicated operation steps and professional operators. Therefore, the development of green, convenient, rapidly responding, multifunctional, highly sensitive and selective sensors is urgently needed.

Due to their various advantages of portable, realtime detection and flexible, the membrane materials have aroused a widespread interest of researchers. Until now, membrane materials are mainly inorganic matrices (e.g. metal oxides and ceramics) and organic substrates (Lee et al. 2019; Bassyouni et al. 2019; Weishaupt et al. 2020). However, inorganic matrices have the disadvantages of high cost, difficult processing and small market application scale, while organic substrates exhibit the advantages of low cost, easy processing and large market application scale. As a new organic and green substrate, cellulose-based membranes possess a series of advantages of environmentally friendly, excellent biodegradability and compatibility, which are extensively applied to sensing fields (Dai et al. 2020). Cellulose membranes are mainly prepared by vacuum filtration, solution regeneration, electrospinning, solution casting, phase inversion and other preparation methods (Mautner 2020; Douglass et al. 2017; Thakur and Voicu 2016). The raw materials for cellulose membranes preparation can include ethyl cellulose, cellulose nanofibers, cellulose nanocrystals, cellulose acetate, triacetyl cellulose, sodium carboxymethyl cellulose, nitrocellulose, etc. (Fu et al. 2019; Zhu et al. 2019a, b; Li et al. 2017a, b, c; Amin 2015; Duong et al. 2018; Hittini et al. 2020; Tang et al. 2019). The excellent sensing performances can be obtained by introducing metal nanowires, metal nanoparticles, carbon dots, quantum dots, carbon nanotubes, fluorophores, organic dyes and antigen-antibodies into cellulose membranes through physical-chemical methods (Lou et al. 2020; Zhang et al. 2019a, b, c; Jiang et al. 2020a, b; Li et al. 2017a, b, c; Lv et al. 2019a, b; Shankar et al. 2020).

As far as we know, there are a few reviews on cellulose-based membranes for sensing applications.
In this review, we summarize the recent developments of cellulose-based membranes as physical sensors, chemical sensors and biosensors over the past five years. As well, the challenges and development prospects of cellulose membrane-based sensors are briefly discussed.

\section{Physical sensors}

\section{Pressure/strain sensors}

With the acceleration of life rhythm and pressure, realtime human motion sensing and pulse monitoring become increasingly important. Body motions can fully reflect the physiological states of human body. Pulse wave is closely related to various physiological diseases, which is of great significance to evaluate the health status of the body and prevent diseases. At present, traditional approaches of visual method, sound method and oscillometric method are mainly used for body motion sensing and pulse monitoring, which exist many deficiencies of complex structure, complicated fabrication process, required external power, trained technicians, poor portability and compatibility, etc. (Yang et al. 2019; Regev and Wulich 2019). Therefore, it is urgent to develop simple, dynamic, timely, sensitive, breathable, wearable and energy-sustainable pressure sensors for monitoring body motion and pulse wave.

Li Zhaoling and co-workers developed a selfpowered and triboelectric all-fiber structured pressure sensor via the electrospinning technique, which was consisted of polyvinylidene fluoride/silver nanowires nanofibrous membrane (PVDF/Ag NWs NFM) as the negatively triboelectric layer, ethyl cellulose nanofibrous membrane (EC NFM) as the positively triboelectric layer and two layers of conductive fabrics on the flexible polydimethylsiloxane (PDMS) substrate (Fig. 1a) (Lou et al. 2020). The incorporation of hierarchically rough structure into the nanofibers could improve the sensing performances of this wearable sensor, which could be prepared by phase separation approach using mixed solutions with different solvent ratios. Furthermore, the triboelectric properties of the nanofibrous membranes had an important influence on the sensitivity of pressure sensor. The results demonstrated that the sensing mechanism of this pressure sensor in the approaching/ 
(a)

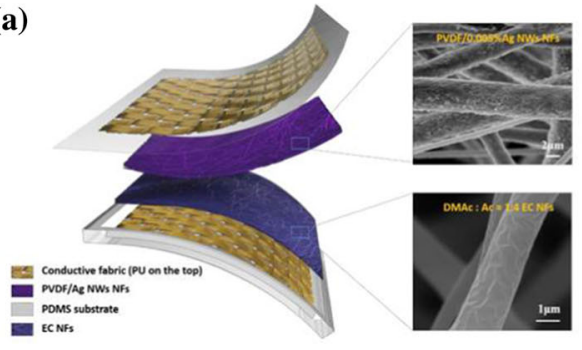

(d)

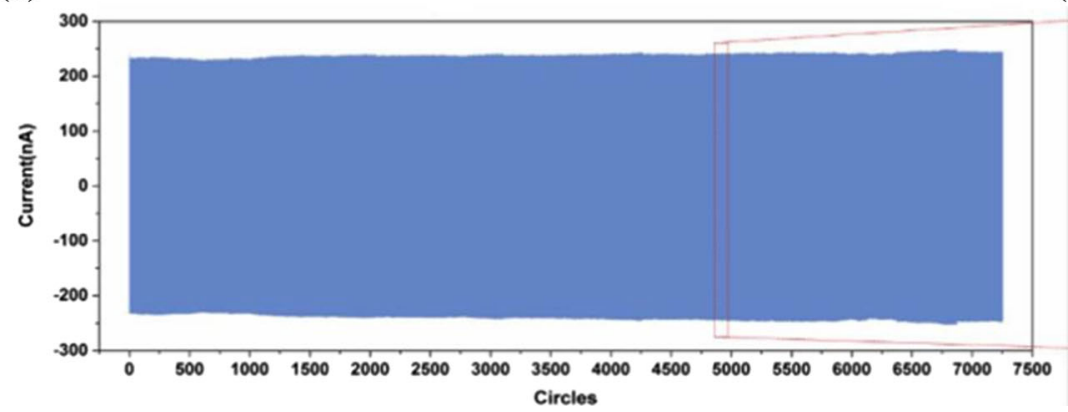

(b)

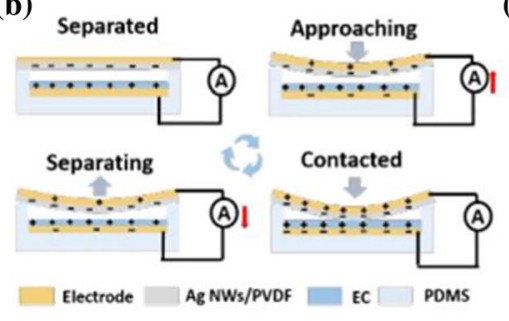

(c)

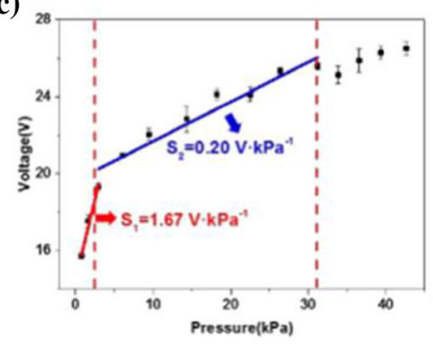

(e)

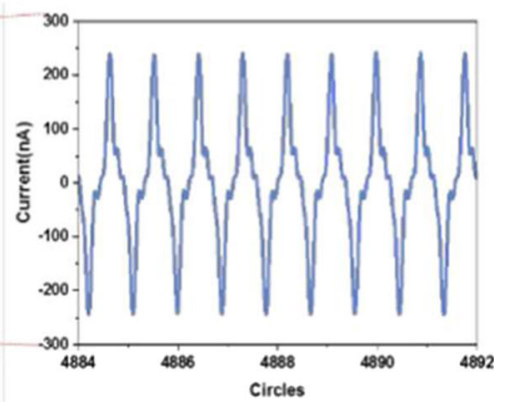

Fig. 1 a The structural design of this pressure sensor textile. b Working mechanisms of the pressure sensor. c Electrical signals in term of output voltage as a function of the applied

separating mode was attributed to the effects of contact electrification and electrostatic induction (Fig. 1b). A pressure range (0-3 kPa) with LOD (limit of detection) of $1.67 \mathrm{~V} \mathrm{kPa}^{-1}$ and a pressure range (3-32 $\mathrm{kPa}$ ) with LOD of $0.20 \mathrm{~V} \mathrm{kPa}^{-1}$ were obtained (Fig. 1c). After 7200 cycles' of continuous operation, the current output of this sensor did not even show obvious changes, which showed that the pressure device had an excellent stability (Fig. 1d). In addition, the pressure sensor can work in a self-powered manner for detecting and quantifying various human motions on different body parts, such as elbows, knees and ankles. This high-performance pressure-sensitive membrane can be extensively applied for wearable electronics and artificial intelligence areas.

Carbon nanotubes (CNTs) with a cylindrical nanostructure have excellent physical properties, which can be widely used in the field of conductive films (Jheng et al. 2019). Lokendra Pal and co-workers developed a capacitive pressure sensor, by placing a piece of insulating crepe paper between two layers of cellulose nanofibers/multi-walled carbon nanotubes (CNF/MWCNTs) membranes (Zhang et al. 2019a, b, c). When MWCNTs content was $5 \mathrm{wt} \%$, this CNF/MWCNTs membranes showed excellent electrical conductivity (Fig. 2e). However, when an pressure. d Sensing stability test of the pressure sensor under around 7200 working cycles. Adapted with permission from Lou et al. (2020), Copyright 2020, American Chemical Society

external pressure acted on the pressure sensor, the capacitance of the sensors increased with the decrease of the distance between the conductive $\mathrm{CNF} /$ MWCNTs membranes (Fig. 2d). When the pressure was removed, the shape of the sensor returned to its original status due to the inherent stiffness and elasticity of the crepe paper. Moreover, the capacitive pressure sensor exhibited an almost linear relationship on the pressure range from 0 to $10 \mathrm{kPa}$. This conductive membrane provided a great practical potential in electronics applications (e.g. touch screens).

Sun Yueming and co-workers prepared a wellaligned reduced graphene oxide/electrospun cellulose acetate nanofibers (RGO/CA) film as a strain sensor through a facile hot-pressing procedure $(\mathrm{Fu}$ et al. 2019). An ordered fibrous membrane can be obtained by a rotation drum collector. By using the hot-pressing technique, not only GO can be reduced to RGO, but also the mechanical properties and conductivities of the RGO/CA film can be enhanced. More importantly, these $\mathrm{RGO} / \mathrm{CA}$ conductive membranes can be used as strain sensors in a broad deformation range and with versatile deformation types, such as bending and pushing. A strain sensor based on carbon nanotubes/cellulose nanocrystals/electrospun polyurethane membranes was designed by Fu Qiang and 

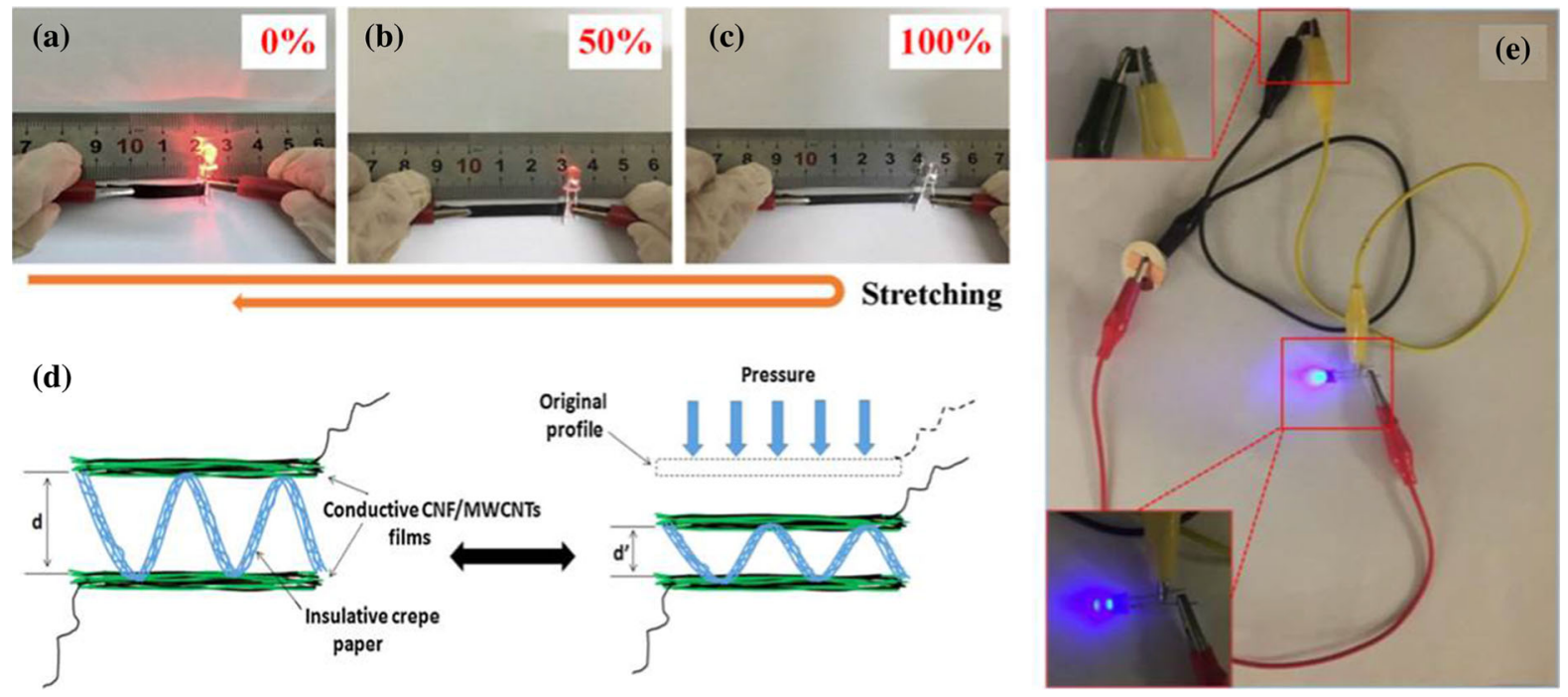

Fig. 2 a-c Visual controlling and the different brightness of a LED indicator under different applied strains by using the strain sensor. Adapted with permission from Zhu et al. (2019a), Copyright 2019, American Chemical Society. d Schematic mechanism of the capacitor after being placed under pressure.

co-workers through one-step simple filtration method (Zhu et al. 2019a, b). When the loadings were below $20 \mathrm{~mL}$, the sensitivities of these sensors improved with the increase of CNT-CNC loadings. When the filler volume was $10 \mathrm{~mL}$, this strain sensor showed a tolerable strain of $500 \%$ without broken and high sensitivity (gauge factor $=321$ ). The brightness of the LED was regulated by this strain sensor, which turned darker with the increase of strain (Fig. 2ac). More interesting, this strain sensor can be applied for monitoring of full-range of human body motions, including phonation, respiration and finger bending, etc. This strain sensor provided an ideal strategy of versatile applications (e.g. human motion detection, electronic skin, intelligent electronics).

\section{Temperature sensors}

Temperature is an important thermodynamic parameter, which affects almost all physicochemical phenomena and chemical reactions (Mazza and Raymo 2019). Therefore, it is very important to monitor the temperature of human activities, the growth of animals and plants, various industrial processes and broad fields (e.g. aerodynamics, meteorology, oceanography and military). Traditional temperature sensing methods have been reported, such as volume expansion e Photographic image of the circuit consisted of the CNF/ MWCNTs membranes with $5 \mathrm{wt} \%$ MWCNTs. Adapted with permission from Zhang et al. (2019a), Copyright 2019, Elsevier B.V.

thermometers, infrared thermometers and other thermocouples, which existed their own intrinsic defects of only measurement of the object surfaces, poor spatial resolution and interference of strong electric and magnetic fields. Thus, it is necessary to design temperature sensors with high sensitivity, long-term stability, fast response, low cost and wide working range.

Rare-earth materials and carbon dots (CDs) have temperature-induced dependencies, which can be applied to temperature sensing (Zhang et al. 2019a, b, c; Jiang et al. 2020a, b). The flexible isotropic films for temperature sensing were prepared by Chen Zhilin and co-workers, which were based on cellulose nanocrystal (CNC)-assisted CDs-grafted $\mathrm{SAO}\left(\mathrm{SrAl}_{2} \mathrm{O}_{4}, \mathrm{Eu}^{2+}, \mathrm{Dy}^{3+}\right)$, and subsequently modified with amino-silane and nanofibrillated cellulose skeletons (Fig. 3a) (Zhang et al. 2019a, b, c). The increase of temperature promoted non-radiant channels of surface defect (or trap) states, thus reduced the PL emission intensity. There was an excellent linear correlation between temperature (243-383 K) and $\mathrm{PL}(506) /(452)$, with the sensitivities of $\mathrm{ONFC} / \mathrm{NH}_{2}$ @CNC-CDs @SAO sensing film $\left(0.257 \% \mathrm{~K}^{-1}\right)$ and CDs-dipping ONFC sensing film $\left(0.270 \% \mathrm{~K}^{-1}\right)$ at $383 \mathrm{~K}$, respectively. Besides, this film exhibited high light-induced scattering, good flexibility and 
(a)

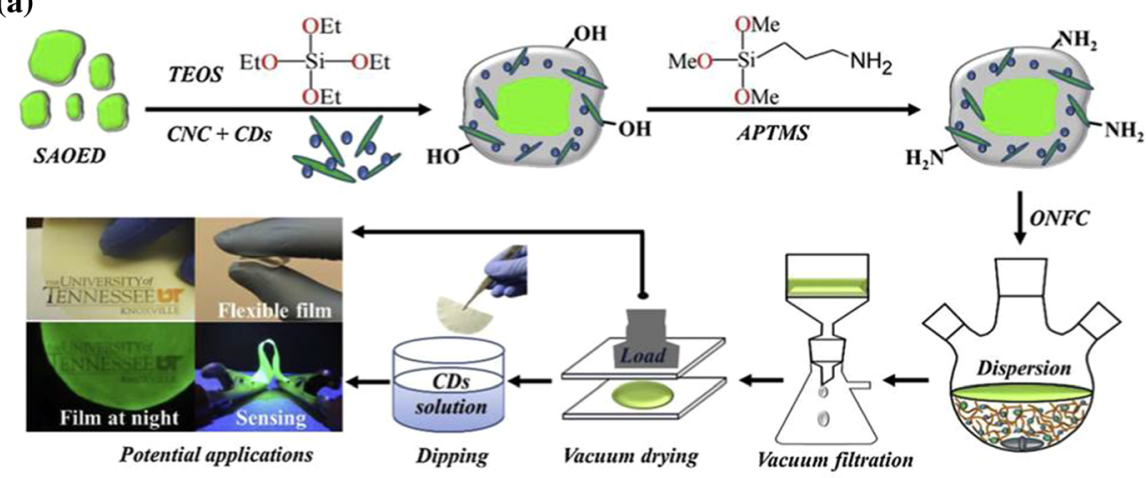

(b)

Water soluble and

hydrophilic

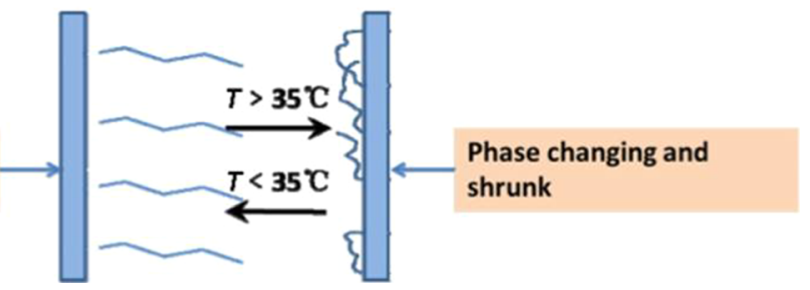

Fig. 3 a Schematic illustration of the preparation of flexible ONFC fluorescent scattering films for temperature sensing. Adapted with permission from Zhang et al. (2019c), Copyright 2019, Elsevier B.V. b The mechanism of temperature

reversibility. Jaehwan Kim and co-workers developed a reduced graphene oxide (rGO)/cellulose composite film as a temperature sensor (Sadasivuni et al. 2015). According to tunneling conduction mechanisms, the capacitance of these films increased with the increase of temperature. These films can be served as excellent candidates for temperature monitoring in the future practical applications.

A novel cellulose acetate (CA) ultrafiltration membrane modified with block copolymer polyethylene oxide-polypropylene oxide-polyethylene oxide/ poly(2-(dimethylamino) ethyl methacrylate) F127-bPDMAEMA through phase inversion method was prepared by Zhou Jiancheng and co-workers, with stimuli-responsiveness to temperature ( $\mathrm{Li}$ et al. 2017a, b, c). As an amphiphilic additive, F127-bPDMAEMA can change the pore structure of this membrane and improve their porosity, which can contribute to increase the sensitivity of this membrane towards temperature. When the temperature was higher than $35{ }^{\circ} \mathrm{C}$, the pure water fluxes of this membrane increased obviously. When the temperature was higher than the lower critical solution temperature LCST $\left(35^{\circ} \mathrm{C}\right)$, PDMAEMA shrunk and released the place for the membrane pores. However, when it was responsiveness of the membrane. Adapted with permission from Li et al. (2017c), Copyright 2019, Wiley-VCH Verlag $\mathrm{GmbH} \& \mathrm{Co} . \mathrm{KGaA}$

lower than LCST, PDMAEMA extended, subsequently occupied the space and made the pores smaller (Fig. 3b). Besides, this membrane also had a stimuli-responsive effect on $\mathrm{pH}(2-14)$. However, the performances of this temperature-sensing membrane were still unsatisfied, and more novel high quality temperature-responsive cellulose-based membranes should be urgently developed.

\section{Humidity sensors}

Relative humidity measurement is very important in the fields of meteorology, industrial process control, agricultural planting and food storage. Moreover, the measurement of human body humidity is of great significance to the evaluation of human health. According to the change of physical parameters after interaction with water molecules, humidity sensors can be divided into capacitance type, resistance type, impedance type, optical fiber type, etc. (Blank et al. 2016; Lv et al. 2019a, b). However, most of the commercially available humidity sensors were based on porous ceramics or metal oxides, which existed some shortcomings, such as the rigid structure, the complicated integration process, the restricted 
accuracy and sensitivity under high temperature or humidity (Wang et al. 2016a, b; Shaheen et al. 2020). Therefore, it is vital to develop the humidity sensors with flexibility, wide response range, fast response, high sensitivity and low hysteresis.

A flexible cellulose nanofiber/carbon nanotube (NFC/CNT) humidity sensor was designed by Chen Gang and co-workers through vacuum filtration technique (Zhu et al. 2019a, b). The introduction of NFC can improve the humidity sensitive performance of CNTs network, because massive hydroxyl groups in cellulose molecular chains can firmly absorb water molecules. When CNT weight ratio was 5\%, the current decreased almost linearly with the increase of relative humidity $11-95 \%$. The NFC/CNT-5 wt \% exhibited a high sensitivity with $69.9 \%$ at $95 \%$ relative humidity. In addition, this humidity film-sensor realized human breath monitoring at different rates (Fig. 4). A self-standing humidity sensor was prepared by Gary Chinga-Carrasco and co-workers through directly printed carbon-based interdigitated electrodes (IDEs) onto CNF/poly(ethylene glycol) (PEG) films (Syrový et al. 2019). PEG not only improved the mechanical properties of CNF films, but also had a positive effect on the printing properties of $\mathrm{CNF}$ substrates. This film sensor demonstrated that the impedance decreased with the increase of relative humidity (20-90\%). However, the longer response and recovery time of CNF/PEG film sensors were needed. These film sensors offered a potential humidity measurement method in scientific and industrial fields.

\section{Chemical sensors}

Metal cations sensors

Metal-ions pollution mainly comes from industrial, traffic and domestic waste, which has seriously threatened the safety of drinking water, industrial and agricultural water sources. Excessive intake of metal ions can lead to serious diseases and even death. However, the traditional instrument techniques for metal-ions measurement have various disadvantages, such as expensive instrument, complicated sample preparation procedure, time-consuming, long analysis time and professional operation. Therefore, the (a)

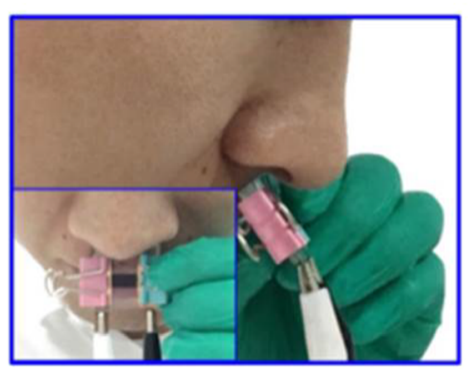

(c)

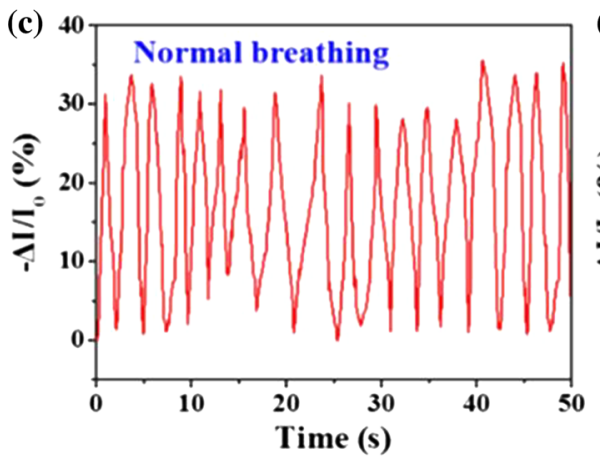

(b)
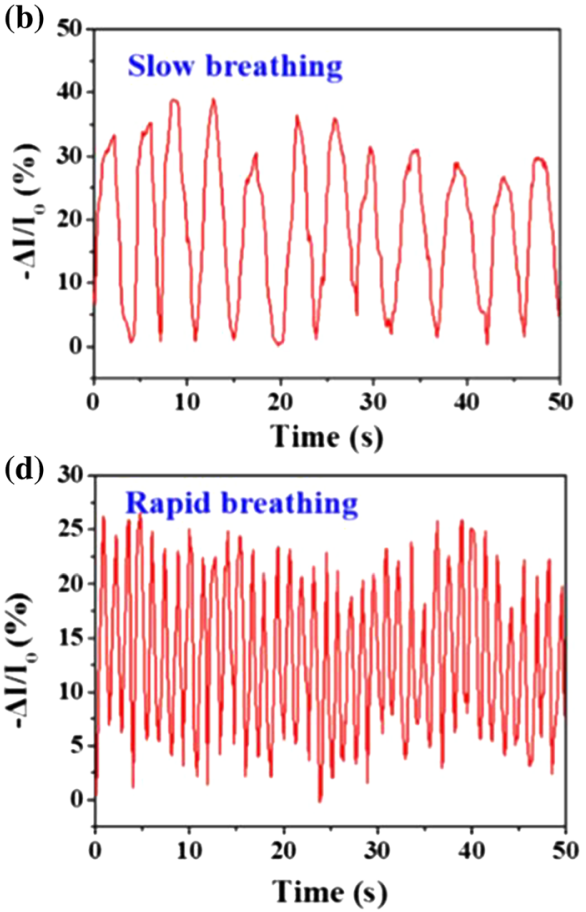

Fig. 4 The application of the NFC/CNT humidity sensor for human breath monitoring at $\mathbf{a}, \mathbf{b}$ slow, $\mathbf{c}$ normal, $\mathbf{d}$ rapid frequency. Adapted with permission from Zhu et al. (2019b), Copyright 2019, American Chemical Society 
development of green, fast, efficient, convenient, highly sensitive and selective methods for metal ions detection is particularly important.

Rhodamine derivatives can be served as various metal ions probes, because of their excellent photophysical characteristics (Ye et al. 2020). A cellulose triacetate membrane immobilized Rhodamine 6G phenylthiosemicarbazide derivative (Rh6G-P) through room temperature solution casting method was prepared by Sangita D. Kumar and co-workers (Thakur et al. 2015). When the opening of spirolactum ring was induced by $\mathrm{Hg}^{2+}$ ions, the naked-eye color of the colorless membrane sensor turned pink (Fig. 5a). This sensor had successfully realized the

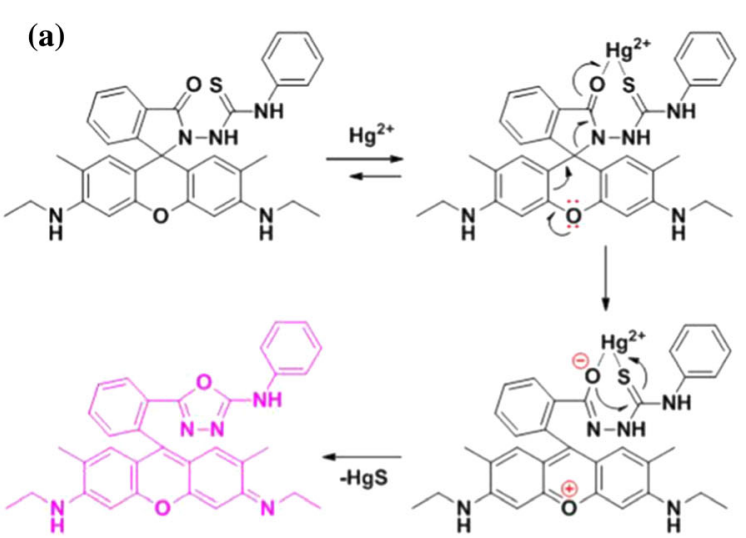

(c)

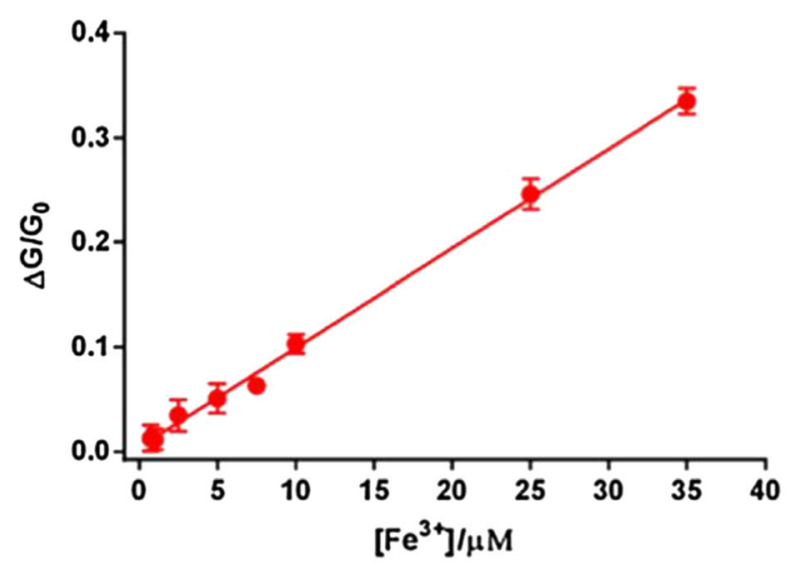

Fig. $5 \mathrm{a} \mathrm{Hg}^{2+}$ recognition mechanism by the incorporated Rh6G-P derivative in the optode. Adapted with permission from Thakur et al. (2015), Copyright 2015, Elsevier B.V. b Cd ${ }^{2+}$ ions detection mechanism with the sensor strips. Adapted with permission from Jiang et al. (2020a), Copyright 2020, American Chemical Society. c The relationship between colorimetric determination of $\mathrm{Hg}^{2+}$ ions in a wide linear range of $10-5000 \mathrm{ng} / \mathrm{mL}$ with LOD of $1.3 \mathrm{ng} / \mathrm{mL}$. Similarly, 5-(2',4'-dimethylphenylazo)-6-hydroxy-pyrimidine-

2,4-dione (DMPAHPD) can be acted as metal-ions probes (Amin and Ahmed 2010). Amin (2015) designed a triacetylcellulose membrane loaded with DMPAHPD dyes for detecting $\mathrm{Hg}^{2+}$ ions. The complex formation occurred between $\mathrm{Hg}^{2+}$ ions and this membrane, which led to the color change from orange to deep red. The membrane sensor exhibited a lower LOD of $0.3 \mathrm{ng} / \mathrm{mL}$ over a linear concentration range of $1.0-80 \mathrm{ng} / \mathrm{mL}$. These proposed sensing membranes may be promising candidates for the determination of $\mathrm{Hg}^{2+}$ ions in the actual water samples.
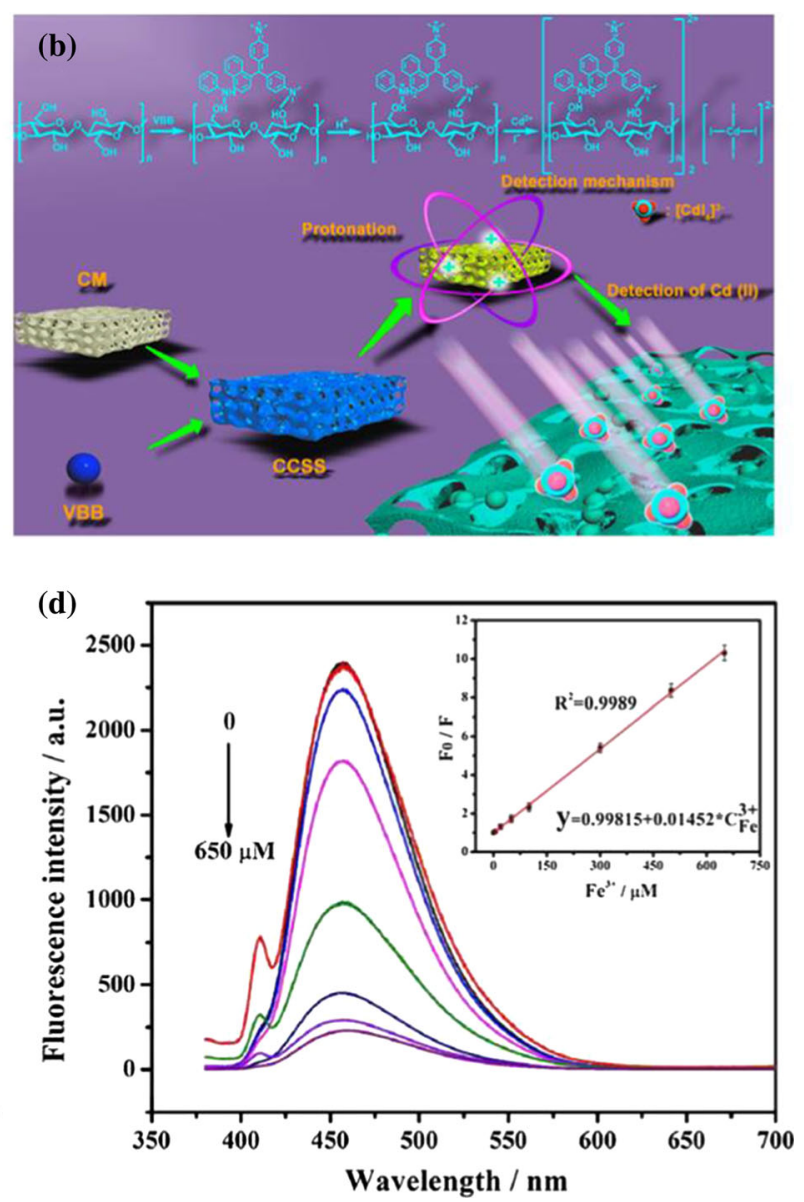

response and $\mathrm{Fe}^{3+}$ concentrations. Adapted with permission from Li et al. (2017b), Copyright 2017, Elsevier B.V. d The FL intensity of the BC/N-GOQDs with different $\mathrm{Fe}^{3+}$ concentrations. Inset: The linear relationship between FL intensities and $\mathrm{Fe}^{3+}$ concentrations. Adapted with permission from $\mathrm{Lv}$ et al. (2019b), Copyright 2019, Springer 
A cellulose membrane-based colorimetric sensor strip (CCSS) functionalized with victoria blue B (VBB, as an indicator) through intermolecular hydrogen bonds was developed by Luo Xiaogang and coworkers (Jiang et al. 2020a, b). Figure 5b showed design scheme of CCSS and detection mechanism of CCSS with $\mathrm{Cd}^{2+}$ ions. When added with $\mathrm{Cd}^{2+}$, the color of CCSS was observed from yellow to bluegreen by the naked eye. Moreover, a visual sensitivity limit $0.01 \mathrm{mg} / \mathrm{L}$ was obtained. This sensing system CCSS was successfully applied to discriminate $\mathrm{Cd}^{2+}$ in real waters.

Naphthalimide derivatives presented high fluorescence quantum yield, good photo-stability and long emission wavelength, which can be acted as metal ions sensors (Liu et al. 2020). Xiao Huining and co-workers constructed a green cellulose membrane (NGC), which coated with graphene oxide (GO) and naphthalimide molecule through hydrogen bonding and $\pi-$ $\pi$ stacking (Li et al. 2018). Because the coordination of piperazine units and $\mathrm{Cu}^{2+}$ ions blocked photo-induced electron transfer (PET) effect, the NGC membrane with $\mathrm{Cu}^{2+}$ appeared a strong fluorescence emission peak at $510 \mathrm{~nm}$ compared to the previously NGC membrane without $\mathrm{Cu}^{2+}$. Besides, a detection limit $0.73 \mu \mathrm{M}$ was achieved. CdTe quantum dots (CdTe QDs) can be worked as the sensing platform for metal ions detection (Elmizadeh et al. 2017). Wu Yiwei and co-workers synthesized a ratiometric fluorescent cellulose acetate membrane, which was immersed in CdTe QDs/graphite carbon nitride (GCNNs) solutions (He et al. 2020). With the increase of $\mathrm{Cu}^{2+}$ concentrations, the color of this membrane sensor was gradually changed from pink yellow to blue under UV lamp. Moreover, a wide semi-quantitative range (0.01-5.0 $\mu \mathrm{g} / \mathrm{mL})$ for $\mathrm{Cu}^{2+}$ detection was obtained. All these results suggested that the cellulose membranes offered a convenient, reliable method for onsite detection of $\mathrm{Cu}^{2+}$ ions in practical waters, such as red wine and drinking water.

Gold nanoparticles (AuNPs) have been widely used in sensing fields due to their excellent photo-physical properties (Rao et al. 2019). Hou Changjun designed a colorimetric paper-based membrane sensor through the process of $\mathrm{TiO}_{2}$ modification, hydrophobic/hydrophilic coating, $-\mathrm{NH}_{2}$ and $-\mathrm{SH}$ groups decoration, and AuNPs immobilization (Li et al. 2017a, b, c). With the increase of $\mathrm{Fe}^{3+}$ concentrations, the original reddish intensity of the membrane gradually decreased. In addition, a detection limit $0.85 \mu \mathrm{M}$ was obtained with a linear relationship between colorimetric response and $\mathrm{Fe}^{3+}$ concentrations (1.0-37 $\mu \mathrm{M})$ (Fig. 5c). Graphene oxide quantum dots (GOQDs) exhibited outstanding optoelectronic characteristics, which have attracted many interests in sensing areas (Park and Seo 2019). A bacterial cellulose/nitrogen-doped graphene oxide quantum dot-based fluorescent membrane (BC/N-GOQDs) through a one-step self-assembly and in situ cultivation strategy (via hydrogen bonding) was synthesized by Wei Qufu and co-workers (Lv et al. 2019a, b). The strong coordination of surface functional groups in BC/N-GOQDs and $\mathrm{Fe}^{3+}$ ions caused blue fluorescence quenching. More importantly, the BC/N-GOQDs sensor presented an outstanding selectivity for $\mathrm{Fe}^{3+}$ ions $(0.5-650 \mu \mathrm{M})$ with an ultralow detection limit $69 \mathrm{nM}$ (Fig. 5d). These cellulose membranes provided a potential for $\mathrm{Fe}^{3+}$ determination in real water samples (e.g. lake waters, serum and mineral waters).

A cellulose membrane functionalized with 1,4dihydroxyanthraquinone (1,4-DHAQ) and carbon nanotubes (CNTs) was fabricated by Wang Meiling and co-workers ( $\mathrm{Gu}$ et al. 2017). In the presence of $\mathrm{Cu}^{2+}$ ions, the fluorescence intensity of the 1 , 4-DHAQ-doped CNTs@CL membrane decreased significantly. A linear range for $\mathrm{Cu}^{2+}$ detection $(0-0.022 \mu \mathrm{M})$ and a detection limit $0.00217 \mu \mathrm{M}$ was achieved. What is more surprising is that fluorescence emission was released when $\mathrm{Cr}^{3+}$ ions were added to the mixture of $\mathrm{Cu}^{2+}$ ions and 1,4-DHAQ-doped CNTs@CL membrane. Meanwhile, a linear equation of $\mathrm{Cr}^{3+}$ ions concentrations $(0-0.024 \mu \mathrm{M})$ and LOD $(0.00221 \mu \mathrm{M})$ was obtained. However, the presence of $\mathrm{Cr}^{3+}$ ions may interfere with the detection of $\mathrm{Cr}^{6+}$ ions. Rafal Sitko and co-workers prepared the aminosilanized cellulose membrane for realizing selective $\mathrm{Cr}^{6+}$ ions detection in the presence of $\mathrm{Cr}^{3+}$ (Jamroz et al. 2019). An excellent sensitivity with LOD of $0.16 \mathrm{ng} / \mathrm{mL}$ indicated that the membrane sensing system had a great promising in recognizing $\mathrm{Cr}^{6+}$ ions in real applications.

A colorimetric paper-based membrane sensor for $\mathrm{Ni}^{2+}$ determination was developed by Hou Changjun and co-workers, through a preparation procedure of $\mathrm{TiO}_{2}$ coating, calcination, hexadecyltrimethoxysilane (HTDES) and hydrophilic modification ( $\mathrm{Li}$ et al. 2017a, b, c). The membrane sensor using zincon/ hollow $\mathrm{ZnSiO}_{3}$ nanospheres/ $\mathrm{Na}_{2}$-EDTA solutions 
presented a dynamic range $(0.65-89 \mu \mathrm{M})$ and a calculated detection limit $0.68 \mu \mathrm{M}$. The color change of membrane sensor from pink to grey was attributed to indicator displacement mechanism. Silver staining technology is extensively applied to ultra-trace sensing fields because of its excellent signal amplification (Tang et al. 2010; Qi et al. 2010). A cellulose acetate membrane (CAM) decorating with dithizone (Dz) for detecting $\mathrm{Pb}^{2+}$ and $\mathrm{Cd}^{2+}$ ions was prepared by Zhao Yuandi and co-workers, with chemical bath deposition and silver stain technology (Wang et al. 2016a, b). The original gray color of the membrane sensor was changed to black (observing by naked-eye) when contacting with $\mathrm{Pb}^{2+}$ or $\mathrm{Cd}^{2+}$ ions. There was a linear fitting over $\mathrm{Pb}^{2+} / \mathrm{Cd}^{2+}$ concentrations (1-100 nM), and simultaneously an extremely low visual detection limit $1 \mathrm{nM}$ was obtained. This chemosensor provided a convenient technique for $\mathrm{Pb}^{2+} / \mathrm{Cd}^{2+}$ detection in practical wastewaters.

Non-metal ions sensors

Chloride ions $\left(\mathrm{Cl}^{-}\right)$permeation can cause the erosion of concrete buildings in harsh environments and then lead to reduction of the strength, utility and aesthetic quality of the concrete structure (Angst et al. 2009). Therefore, it is of great significance to monitor $\mathrm{Cl}^{-}$ ions in concrete environment. A novel fiber optic probe based on cellulose acetate (CA) film immobilizing lucigenin-doped silica nanoparticles via physical embedding was developed by Ding Liyun and coworkers (Xiao et al. 2019). This sensitive film can be served as a highly selective probe for detecting $\mathrm{Cl}^{-}$ ions in $\mathrm{KCl}$ solutions. Based on fluorescence quenching principle, a linear relationship between fluorescence intensity and $\mathrm{Cl}^{-}$ions concentrations (0.02-0.06 M) was obtained (Fig. 6a). This material had various advantages of simplicity, convenience and efficiency in selective identification of $\mathrm{Cl}^{-}$ions in building fields.

Nitrate ions $\left(\mathrm{NO}_{3}{ }^{-}\right)$can lead to the pollution of water systems (e.g. lakes, rivers, seas and oceans), because of the eutrophication of algae. Furthermore, nitrate is very harmful to human, especially to infant. Therefore, it is very urgent to realize the rapid detection of nitrate in water environment. Jong Il Rhee and co-workers reported an oxazine170 perchlorate-ethyl cellulose (O17-EC) membrane with a clay hydrotalcite (HT, working as a reducing reagent for reduction of nitrate to ammonia) for colorimetric and ratiometric detection of nitrate (Duong et al. 2018). When the concentrations of nitrate increased from $0.1 \mathrm{mM}$ to $10 \mathrm{mM}$, the color transition of the O17-HT-EC membrane was clearly observed under an excitation wavelength $(470 \mathrm{~nm})$ irradiation (Fig. 6b). The membrane sensor demonstrated a highly selective in the detection range $(0.1-1.0 \mathrm{mM})$ with a sensitive detection limit $0.089 \mathrm{mM}$. Meanwhile, this sensor exhibited a fast response time ( $\sim 10 \mathrm{~s})$ and long-term stability ( $>1$ month) and outstanding reversibility, which suggested that the novel approach can recognize nitrate in real water samples instead of traditional methods (e.g. flow injection analysis and molecular emission cavity analysis).

Due to its toxicity and bioaccumulation, a high intake of Selenium(IV) can cause dangerous diseases to living organisms (Ventura et al. 2009). Thus, the development of a convenient and highly efficient method for determinating Se(IV) is extremely important. Preeti Sunil Kulkarni prepared a cellulose triacetate plasticized membrane modified with trioctyl methyl ammonium chloride (Al-336, as an ion exchanger) (Kulkarni et al. 2018). This sensor exhibited a highly selective for Se(IV), and was not influenced by the other interfering anions, such as oxalate, phosphate, nitrate, bicarbonate, bromate, and chloride. The sensing process can be briefly described as follows: first, iodometric method happened between $\mathrm{Se}$ (IV) and iodide ions in acidic medium (from colorless to yellow color); second, tri-iodide anion $\left(\mathrm{I}_{3}{ }^{-}\right)$reacted with variamine blue dye in sodium acetate solutions (from yellow to violet) (Fig. 6c). A good linear range $(0.2-3 \mu \mathrm{g} / \mathrm{mL})$ and LOD value $(0.15 \mu \mathrm{g} / \mathrm{mL})$ indicated that the material can be served as an ideal method for the determination of Se(IV) in pharmaceutical industries.

Excessive As(III) is related to a series diseases of cancers, diabetes and reproductive problems (Hao et al. 2009). A cellulose/amorphous silica/(3-mercaptopropyl)-trimethoxysilane membrane for highly selective adsorption and detection of As(III) was developed by Rafal Sitko and co-workers (Fig. 6d) (Lukojko et al. 2018). Due to the strong binding ability between As(III) and mercapto groups, this membrane material displayed excellent selectivity for ultra-trace $\mathrm{As}(\mathrm{III})$ detection in the presence of interfering ions, including $\mathrm{As}(\mathrm{V})$, heavy metals (e.g. $\mathrm{Pb}^{2+}, \mathrm{Ni}^{2+}$ and $\mathrm{Co}^{2+}$ ) and anions (e.g. $\mathrm{SO}_{4}{ }^{2-}, \mathrm{NO}_{3}{ }^{-}$and $\mathrm{Cl}^{-}$). More 
(a)

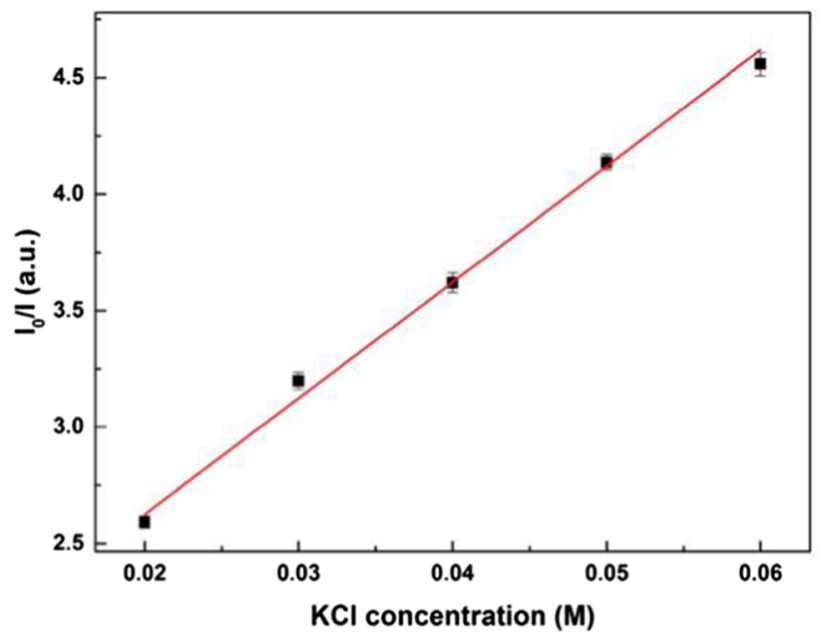

(c)
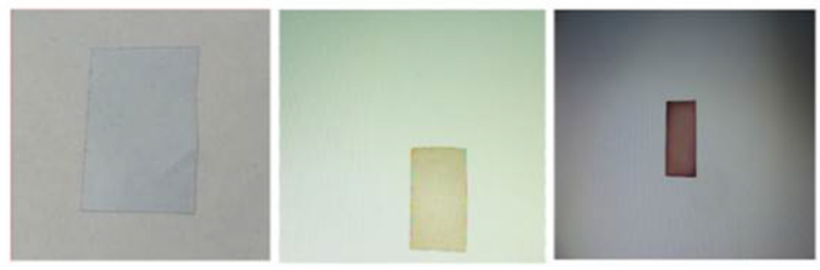

(b)

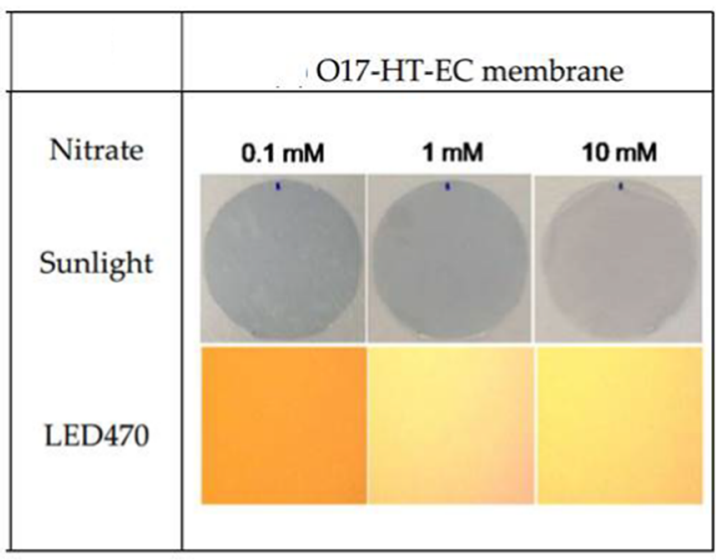

(d)

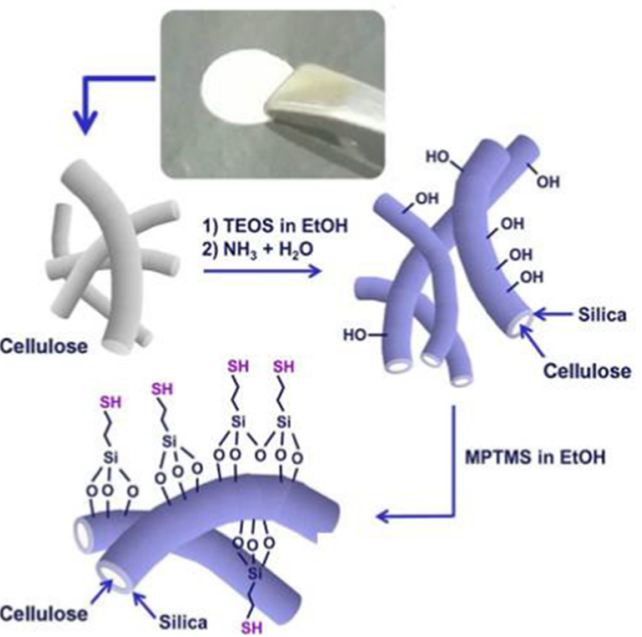

Fig. 6 a Calibration curve of optical fiber sensing probe response to $\mathrm{Cl}^{-}$by $\mathrm{KCl}$ standard solutions. Adapted with permission from Xiao et al. (2019), Copyright 2019, Elsevier B.V. b The photo images of the O17-HT-EC membranes with different nitrate concentrations under sunlight or LED $(470 \mathrm{~nm})$ irradiation. Adapted with permission from Duong et al. (2018),

importantly, the miniaturized membrane achieved a linear range $0.2-200 \mathrm{ng} / \mathrm{mL}$ and an extremely low detection limit $0.045 \mathrm{ng} / \mathrm{mL}$, which was considerably lower than the maximum allowable value $10 \mathrm{ng} / \mathrm{mL}$ of As(III) in drinking water according to World Health Organization. This novel sensing platform offered a solvent-free, low cost and environmental-friendly method in determination of As(III) in high salinity water. However, realizing efficient detection of $\mathrm{As}(\mathrm{V})$ is still a huge challenge.

The efficient combination of sensors with Internet of things (IOT) provides great potential for a stable renewable energy system (Bethke et al. 2018). Woo Soo
Copyright 2018, MDPI, Basel, Switzerland. c The color change of films sorbed with $\mathrm{I}_{3}{ }^{-}$and after treatment with variamine blue. Adapted with permission from Kulkarni et al. (2018), Copyright 2018, Springer. d The preparation process of cellulose/ $/ \mathrm{SiO}_{2} /$ MPTMS membranes. Adapted with permission from Lukojko et al. (2018), Copyright 2018, Elsevier B.V.

Kim and co-workers constructed a 3D printed disposable wireless ion selective sensor for $\mathrm{NH}_{4}{ }^{+}$detection, which was consisted of AgNWs, cellulose nanofibers and polyimide (Kim et al. 2019). Through measuring the magnitude of reflection coefficient $S_{11}$, the change of $\mathrm{NH}_{4}{ }^{+}$concentrations on IS-LC sensor was wirelessly detected by VNA, and a high sensitivity of $3.4 \% / \mathrm{M}$ was achieved. This $3 \mathrm{D}$ printed wearable ion sensor can provide an efficient method for the realization of Internet of things and wireless monitoring. 
$\mathrm{pH}$ sensors

$\mathrm{pH}$ (hydrogen ion concentration) is closely related to most areas. $\mathrm{pH}$ value is not only a very important parameter in the industrial, pharmaceutical and food industries, but also has an influence on global ecology and physiological biochemistry (Chu et al. 2013; Koch et al. 2013; Gotor et al. 2017). Besides, pH plays an important role in many chemical and biological processes of animals, plants and bacteria. So far, three methods of electrochemical, photochemical sensors and $\mathrm{pH}$ test paper strips are mainly used to determine $\mathrm{pH}$. Although $\mathrm{pH}$ test paper has the advantages of cheap, wide coverage and simple operation, it does not have high resolution. Even though $\mathrm{pH}$ glass electrode is the most commonly used $\mathrm{pH}$ sensor, it is still interfered by high temperature, high pressure, strong alkali, ionic strength, some organic matters and electromagnetic radiation. However, when the $\mathrm{pH}$ value changed, the optical sensor may read the changes of absorption, fluorescence or reflectivity. Besides, the optical $\mathrm{pH}$ sensor also had the advantages of anti-electromagnetic interference, convenient, low cost, high selectivity and sensitivity. In general, an optical $\mathrm{pH}$ sensor is mainly made of a $\mathrm{pH}$ indicator (acid-based indicators) and an organic carrier (e.g. hydrogel or cellulose) through adsorption, chemical bonding and sol-gel method.

Zhang Jianxin fabricated an optical $\mathrm{pH}$ sensitive membrane via sol-gel method, which was developed by embedding four indicators of congo red, bromophenol blue, cresol red and chlorophenol red into an organic carrier, simultaneously cross-linked by tetraethyl orthosilicate (TEOS) and cellulose acetate (Zhang and Zhou 2018). According to a linear relationship between Power $(\mu \mathrm{W})$ and $\mathrm{pH}$ values, a working detection range (2.5-11.0) was obtained, with a measurement accuracy $(0.2 \mathrm{pH})$ of the sensor. The sensing membrane had a wide response range to $\mathrm{pH}$ values, which was probably attributed to the interaction of the four indicators. Compared with traditional electric chemical electrodes, various advantages (e.g. good stability and repeatability) of this $\mathrm{pH}$ sensor provided a practical evaluation method in the areas of clinical medicine, biopharmaceutical and industrial sewage. However, the sensor needed a long response time and should be activated before normal measurement. Besides, the sensor cannot work well in strong acid $(\mathrm{pH} \leq 2.5)$ and alkali $(\mathrm{pH} \geq 11.0)$ environments.
A pH-responsive sensing platform was produced by Narges Chamkouri, by immobilizing phenol red on the triacetylcellulose membrane (Chamkouri 2015). With the increase of $\mathrm{pH}$ values, the absorbance at $464 \mathrm{~nm}$ of the optical sensor and detected solutions decreased. Their results showed that the $\mathrm{pH}$ sensor maintained a relatively wide linear range (3.0-12.0) with a longterm stability (8 months) in water/ethanol $(50: 50, \mathrm{v} / \mathrm{v})$. In addition, a correlation coefficient (0.999) and relative standard deviations (less than $0.7 \%$ ) supplied a good reliable and accurate platform for monitoring $\mathrm{pH}$ in the future applications.

Because the optical probes depended on indicator transition characteristics, they cannot be used for certain applications. Due to the advantages of high sensitivity and without frequent recalibration, the luminescent $\mathrm{pH}$ sensors had an extensively applicability to practical samples. Lanthanide (Ln) compounds with excellent photo-physical properties played a key role in these fields of luminescent labels, probes, phosphors and biological (Ning et al. 2019; Khullar et al. 2019). A luminescent $\mathrm{pH}$ membrane sensor based on cellulose acetate (CA) and a new europium complex $\left(\mathrm{Eu}^{3+} /\right.$ theonyl trifluoroacetone/gallic acid/pyridine dicarboxylic acid) was prepared by Axel Duerkop and co-workers (Waleed AlQaysi and Duerkop 2018). With the increase of $\mathrm{pH}$ values (2-7), the fluorescence intensity at $615 \mathrm{~nm}$ of the sensing film increased significantly, which was related to the $\mathrm{p} K_{\mathrm{a}} \mathrm{s}$ of the $\mathrm{Eu}^{3+}$-complex. The membrane sensor with advantages of a long response range (2-7) and operational lifetime can apply for high throughput $\mathrm{pH}$ sensing. However, the sensor was still not suitable for alkaline solutions. Although the optical and luminescent $\mathrm{pH}$ sensors had made great progress in $\mathrm{pH}$ detection, they still face the difficult problems to work well in harsh environments, such as high temperature, high pressure, strong acid, strong alkali, etc.

Gas and vapor sensors

Gases are generated from industrial activities, volcanic eruptions, mining and burning of minerals. However, excessive toxic gases are seriously harmful for the health of animals and plants. For example, $\mathrm{H}_{2} \mathrm{~S}$ will damage human respiratory and nerve systems, resulting in unconsciousness (Zhou et al. 2019). $\mathrm{NO}_{2}$ is related to respiratory tract and may cause serious 
diseases of bosom frowsty, difficulty breathing and asthma (Bhat and Pandey 2018). A high concentration of ammonia may bring lung swelling of humans and even death (Masoud et al. 2018). Excessive intake of ethanol vapor will cause irritation of nose, eyes and mucous membrane (Boyes et al. 2014). Therefore, it is very important and urgent to develop green, low cost, fast response, highly selective and sensitive of sensors to monitor toxic gases in environment and industrial processes. According to different physical, chemical and electronic mechanisms, gas sensors can be divided into semiconductor metal oxide sensors, electrochemical sensors, optical sensors, catalytic combustion sensors, etc. Semiconductor metal oxide materials have become the most promising gas sensors because of their low cost, convenient operation, fast response and high sensitivity for target gases detection (Balasubramani 2020). Besides, electrochemical gas sensors work with the measured gas and then output the electrical signal proportional to the gas concentrations. Similarly, electrochemical sensors have the advantages of accuracy, reliability, rapidity and high sensitivity (Wang et al. 2020a, b). However, the optical sensors are based on the reactions between the measured gas and the sensitive layer, which result in changes of absorbance, fluorescence and color (Lochbaum et al. 2020).

The introduction of copper oxide nanoparticles (CuO NPs) with large specific surface and more reactive sites can improve the chemical reactivity and sensitivity of metal oxide semiconducting polymer membranes for gas sensing (Tanvir et al. 2016). Saleh t. Mahmoud and co-workers reported a novel semiconductor membrane sandwiched between a pair of electrodes for $\mathrm{H}_{2} \mathrm{~S}$ sensing, which was prepared by $\mathrm{CuO}$ NPs (via a colloid microwave-assisted hydrothermal method) and sodium carboxymethyl cellulose (CMC) powder with glycerol ionic liquid (5\%) through the solution casting method (Hittini et al. 2020). When the optimum concentration of $\mathrm{CuO}$ was $5 \%$, the nanoparticles were uniformly distributed in the membrane and no agglomeration. According to the change of electric current, the sensor was response to $\mathrm{H}_{2} \mathrm{~S}$ concentrations. Moreover, this sensor presented a decent selectivity towards $\mathrm{H}_{2} \mathrm{~S}$ in the presence of interfering gases (e.g. $\mathrm{C}_{2} \mathrm{H}_{4}$ and $\mathrm{H}_{2}$ ), and a detection limit $15 \mathrm{ppm}$ at a low temperature $\left(40^{\circ} \mathrm{C}\right)$. In addition, this membrane demonstrated a reversible behavior and low humidity dependence. The adsorption and desorption of oxygen molecules can be used to explain the sensing mechanism of the membrane. These results suggested that the membrane provided a reliable sensing platform for $\mathrm{H}_{2} \mathrm{~S}$ detection in harsh environments, such as highly humid and low temperature. Another semiconductor thin film sensor was reported by Estefanía Núñez-Carmona and coworkers based on bacterial cellulose and zinc oxide $(\mathrm{ZnO})$ (Núñez-Carmona et al. 2019). The best response of this sensor for detecting $\mathrm{NO}_{2}$ was obtained. However, this sensor needed the activation of UV lamp, which was not beneficial to be widely used in practical applications.

Graphene oxide (GO) has relatively strong absorption properties of gas molecules, which is attributed to the characteristics of basal surfaces and prismatic edges. Besides, GO has a low permeability of most gases, which is expected to be an effective additive into cellulose-based solid electrolyte for regulating gas permeation. A green solid electrolyte based on cofunctionalized cellulose/GO membrane was developed by Chen Zhongwei and co-workers, as an electrochemical gas sensor for alcohol vapor detection (Zhang et al. 2017). A schematic diagram of an alcohol fuel cell sensor (AFCS) and its electrochemical principle was shown in Fig. 7a. The concentration information of input ethanol vapor can be obtained by collecting the transferred electrons from anode to cathode as electrical signals. This sensor presented excellent selectivity towards ethanol vapor over water and acetone, with a low detection limit $25 \mathrm{ppm}$. Moreover, due to assist protons to move and through the membrane plane, a high water uptake of this cellulose/GO membrane offered promising ionic conductivity. The cellulose/GO membrane was used as an ideal electrochemical device for monitoring ethanol vapor in future practical applications.

Amino acid ionic liquids (AAIL) are green solvents for dissolving cellulose, which can act as the adsorption medium of gas (Uehara et al. 2019). A cellulose acetate membrane modified with a kind of amino acid ionic liquid (ProIL) through the phase inversion method, was designed by Kamatchi Sankaranarayanan and co-workers as an ammonia sensor (Mehta et al. 2020). ProIL was prepared by amino acids L-Proline and IL EMIM OH (base) via the neutralisation method. The sensing of ammonia by this membrane CA-ProIL was mainly based on the change in resistance, which was primarily due to chemisorption 

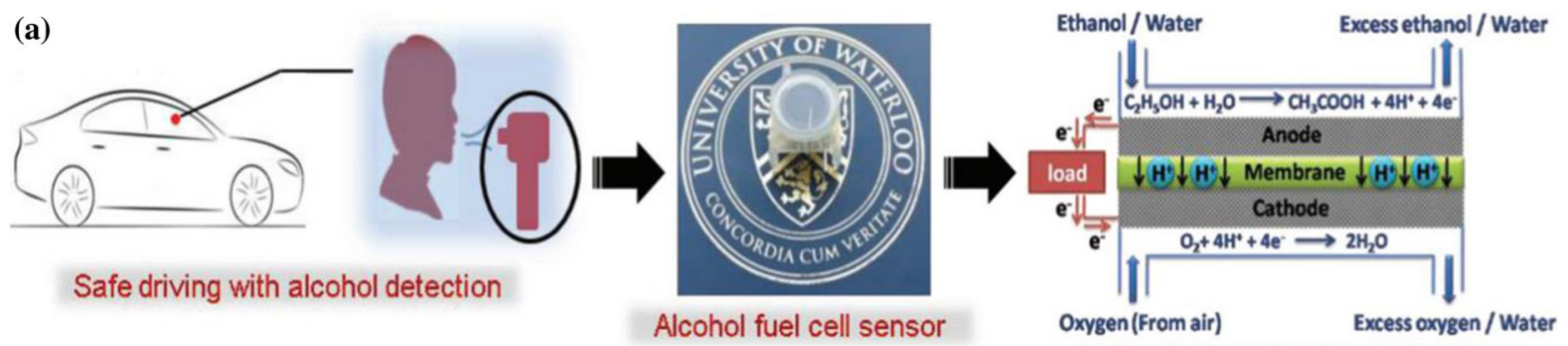

Direct ethanol fuel cell principle

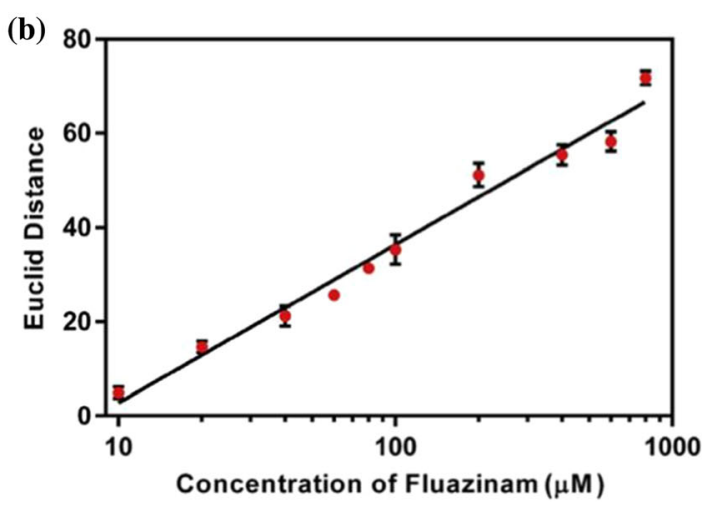

Fig. 7 a Schematic diagram of an AFCS and its electrochemical principle. Adapted with permission from Zhang et al. (2017), Copyright 2017, Wiley-VCH Verlag GmbH \& Co. $\mathrm{KGaA}$. b The linear equation between the euclidean distance and fluazinam concentrations. Adapted with permission from

between ammonia and the surface of membrane. When acetone, ethanol and toluene existed, CA-ProIL showed a high selectivity for ammonia sensing with a low detection value $1 \mathrm{ppm}$ at room temperature. The possible mechanism of adduct formation between ammonia and ProIL had been proved by Nuclear Magnetic Resonance (NMR) spectroscopy. Response time $(60 \mathrm{~s})$ and recovery time (78 s) suggested that this membrane CA-ProIL provided a potential for ammonia sensing in the future industrial areas.

Toxic organic compounds sensors

Pesticides, organic solvents and dyes are toxic and non-degradable. Their unreasonable use and arbitrary discharge would bring serious threats to soil, water, environment and even humans. Therefore, it is very important to develop green, simple, efficient and lowcost sensors for detecting toxic organic compounds instead of the traditional instrument methods.

Low concentration of fluazinam can be used as fungicide to control phytophthora blight (Bakirci et al. (c)

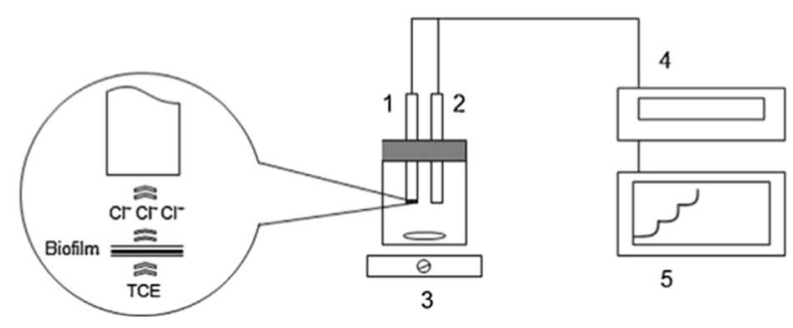

Wang et al. (2020b), Copyright 2020, Elsevier B.V. c Schematic representation of the TCE biosensor assembly. (1) a working electrode, (2) a reference electrode, (3) a stirrer, (4) an ion meter, and (5) a recorder. Adapted with permission from Chee (2016), Copyright 2016, Elsevier B.V.

2014). However, the excess use of fluazinam not only poses a serious threat to environment and food safety, but also reduces the soil quality and destroys the balance of biological population (Feng et al. 2015). $\mathrm{MoS}_{2}$ QDs have the advantages of low toxicity and high stability, so they can be served as convenient, fast and efficient probes in the sensing fields (Wang et al. 2017; Lu et al. 2017). A cellulose membrane crosslinking $\mathrm{MoS}_{2}$ QDs was developed by Hou Changjun and co-workers, which realized nake-eyed and digital readout for detecting fluazinam in vegetable samples (Wang et al. 2020a, b). A overlapping between the absorption peak $(347 \mathrm{~nm})$ of fluazinam and the excitation (322 nm) of $\mathrm{MoS}_{2}$ QDs caused inner filter effect (IFE), which led to the fluorescence quenching of the $\mathrm{MoS}_{2}$ QDs. Thus, this sensor showed a highly selective for fluazinam rather than other similar pesticides, such as omethoate, glyphosate, triadimefon, etc. According to the linear equation between euclidean distance of $\triangle \mathrm{RGB}$ and the logarithm of fluzinam concentration $(10-800 \mu \mathrm{M})$, the detection limit $2.26 \mu \mathrm{M}$ was obtained (Fig. $7 \mathrm{~b}$ ). In addition, $\pi-\pi$ 
stacking, hydrogen bond and electrostatic interaction of fluzinam with $\mathrm{MoS}_{2}$ QDs can improve its selectivity and sensitivity. This proposed platform offered a convenient and efficient approach for fluazinam detection in agriculture and food safety.

Trichloroethylene (TCE) is widely acted as a cleansing agent for electronic parts. However, TCE is seriously harmful for soil and groundwater because of its unreasonable use and leakage. More importantly, TCE can cause serious impairment in the central nervous system when humans expose to a high level. Therefore, it inspires many researchers to develop simple and fast methods for TCE detection. Some studies have shown that an aerobic bacterium of Pseudomonas sp. strain ASA86 can be applied for TCE degradation (Chee 2011). A novel microbial biosensor based on Pseudomonas sp. strain ASA86 was designed by Gab-Joo Chee, utilizing a porous cellulose nitrate membrane with a chloride ion electrode to detect TCE (Chee 2016). After degradation of TCE by bacterium in the biosensor, chloride ions would be released, which can be detected by the ion electrode and output signal then converted into TCE value (Fig. 7c). This biosensor demonstrated a higher selectivity towards TCE than that of other organic solvents, such as 1,1-dichloroethylene, 1,2-dichloroethylene and 1,2-dichloroethane, etc. A good linear relationship of biosensor response with TCE concentrations $(0.05-4 \mathrm{mg} / \mathrm{L})$ was achieved with a detection limit $0.05 \mathrm{mg} / \mathrm{L}$, which was lower than the TCE limit of industrial water and waste water stipulated by Japan. When the biosensor was at optimum conditions of $\mathrm{pH} 8.0$ and $30{ }^{\circ} \mathrm{C}$, the response time was about $5 \mathrm{~min}$. However, the detection limit $0.05 \mathrm{mg} / \mathrm{L}$ of this biosensor was still higher than the limit value $0.03 \mathrm{mg} /$ $\mathrm{L}$ of drinking water standard. Besides, toluene was used in culture medium of bacterium, which left a potential threat to the environment.

Because of its toxicity, mutagenicity, carcinogenicity and non-biodegradable, Methylene blue (MB) derived from dye industries is harmful to environment and humans (Auerbach et al. 2010; Hassan et al. 2014). However, the traditional UV-vis spectrometer for measuring $\mathrm{MB}$ is not suitable for on-site and convenient detection. Xu Xiaoping and co-workers reported a nitrated cellulose acetate (NCA) microfiltration membrane through phase inversion method, as a visual sensor for $\mathrm{MB}$ detection in tap water (He et al. 2016). In the filtration process of trace MB with this membrane, MB molecules can be concentrated on the membrane to achieve a visual response. The membrane displayed a highly selective for $\mathrm{MB}$ detection, which was not influenced by bromophenol blue and crystal violet. When the membrane filtered $30 \mathrm{~mL}$, the naked-eye detection limit $0.001 \mathrm{mg} / \mathrm{L}$ was achieved. Although the membrane sensor realized the portable detection of $\mathrm{MB}$, it needed a large volume of solution.

\section{Biosensors}

\section{Biomolecular sensors}

Realizing the efficient detection of biological molecules in organisms is very important for disease prevention, clinical medicine and other processes. Glucose is widely distributed in human blood, urine, tears, etc. Therefore, glucose needs to be detected in time for preventing a high level, which leads to diabetes. A cellulose-based strips (CBS) was designed by Luo Xiaogang and co-workers, through oxidized cellulose membranes and glucose oxidase $\left(\mathrm{GO}_{\mathrm{X}}\right)$ / horseradish peroxidase (HRP) via schiff-base reaction (Luo et al. 2019). CBS can be used as enzyme colorimetric assay for fast (within $5 \mathrm{~min}$ ), sensitive and naked-eye detection of glucose. A schematic diagram of the preparation of CBS and detection of glucose was shown in Fig. 8a. The sensing mechanism was briefly described as follows: first, $\mathrm{GO}_{\mathrm{X}}$ can catalyze the oxidation of glucose to form $\mathrm{H}_{2} \mathrm{O}_{2}$ by molecular oxygen. An obvious blue color was observed by the reaction of $\mathrm{H}_{2} \mathrm{O}_{2}$ with $3,3^{\prime}, 5,5^{\prime}$ tetramethylbenzidine (TMB) under the oxidation of HRP. CBS presented a highly selective for glucose in presence of other carbohydrates (e.g. lactose, fructose, sucrose and maltose). A good linear relationship between the color intensity (recorded by a simple camera) and glucose concentrations (1-11 mM) was obtained with a detection limit $(0.45 \mathrm{mM})$, which met the normal detection parameter 3.9-6.4 mM of glucose in human serum. In all, CBS provided a semiquantitative approach for glucose detection in areas of biosensors, drug carriers and biomedicine.

Interleukin-6 (IL-6) is a pleiotropic cytokine, which plays an important role in immunity, tissue repair and metabolism, etc. Due to various disadvantages of large sample volume, long incubation time and complicated 

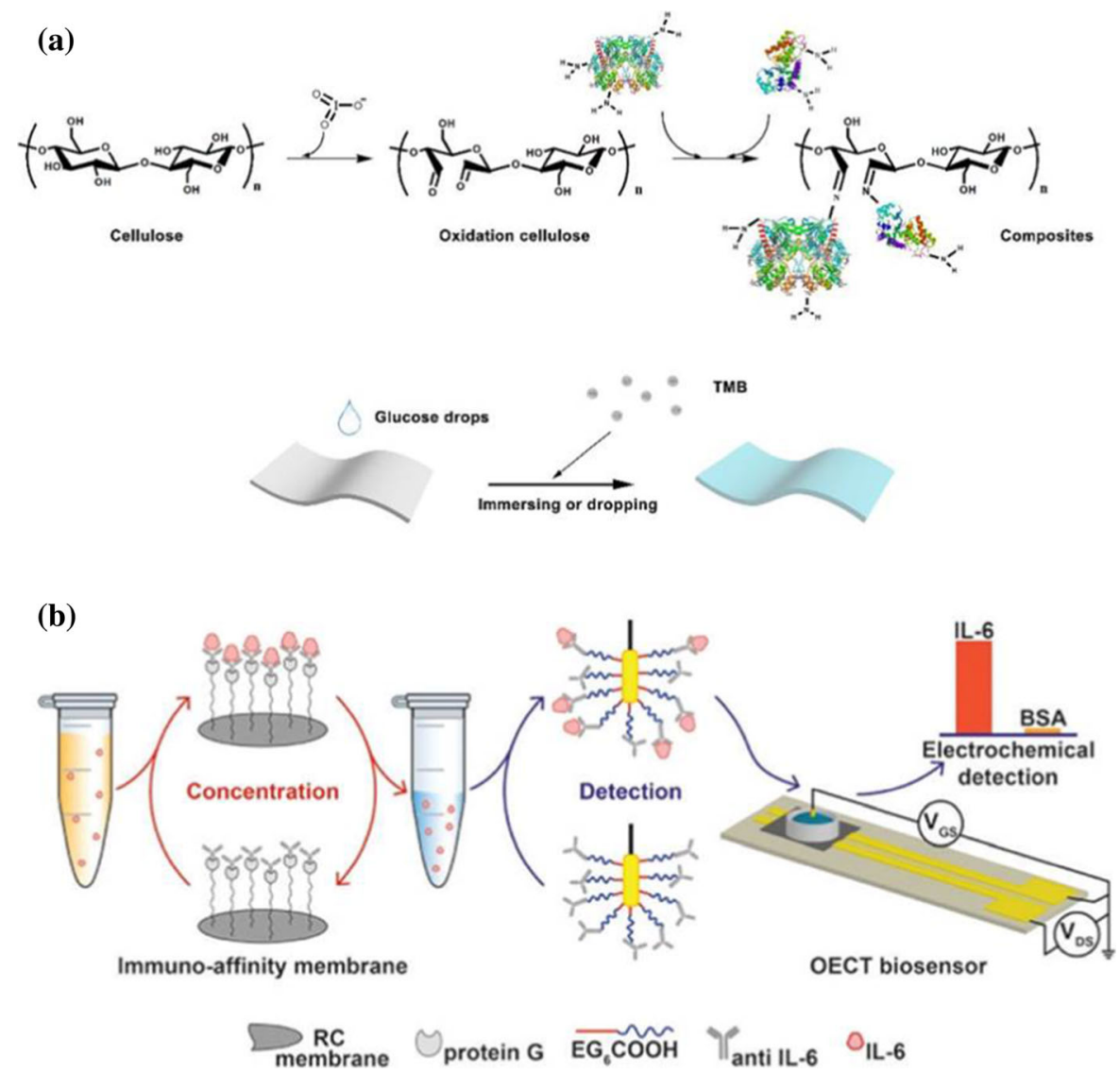

Fig. 8 a The preparation process of the cellulose-based strips and their glucose detection. Adapted with permission from Luo et al. (2019), Copyright 2019, American Chemical Society.

b Schematic illustration of the selective concentration and

sample labelling process, the most common method of enzyme-linked immunosorbent assay (ELISA) is not suitable for real-time or dynamic monitoring of cytokine (Liu et al. 2016). However, the minimizing costs and processing time of label-free approaches can be applied for direct detection of antibody-antigen $(\mathrm{Ab}-\mathrm{Ag})$ recognition events. Besides, organic electrochemical transistors (OECTs) have the advantages of tissue compatibility, high stability and efficient operation, which can be acted as chemical sensors and biosensors (Lin and Yan 2012; Liao et al. 2015; Tang et al. 2011). A label-free and selective approach of IL6 detection was prepared by Denis Gentili and coworkers, through combining an OECT with an immuno-affinity regenerated cellulose membrane (Gentili et al. 2018). The OECT gate electrode can be modified by an oligo (ethylene glycol)-terminated electrochemical detection of IL-6. Adapted with permission from Gentili et al. (2018), Copyright 2018, Royal Society of Chemistry

self-assembled alkanethiolate monolayer (SAM), which can immobilize anti IL-6 antibodies and inhibit non-specific biomolecule binding. Figure $8 \mathrm{~b}$ displayed the schematic diagram of selective concentration and electrochemical detection of IL-6. Antibodyantigen $(\mathrm{Ab}-\mathrm{Ag})$ molecular recognition events occurred in the preconcentrated IL- 6 and anti IL-6 antibodies on the OECT gate electrode, which was converted into physically detectable signals. The preconcentration step of the immune-affinity membrane promoted IL-6 detection in physiological concentration. In addition, a detection limit of IL- 6 was raised to $220 \mathrm{pg} / \mathrm{mL}$.

Plasmodium falciparum histidine-rich protein 2 (PfHRP2) level in whole blood samples can be used as a parameter for diagnosing $P$. falciparum infection (Hendriksen et al. 2013). Similarly, a wash-free and 
label-free immunoassay technique was developed by Peter B. Lillehoj for rapid electrochemical detection of PfHRP2 in whole blood samples (Dutta and Lillehoj 2018). A unique detection method was based on electrochemical-chemical (EC) redox cycling with an affinity-based protein quantification strategy for signal amplification. The detection of PfHRP2 with this immunoassay sensor would not be interfered by other electroactive species (e.g. glucose, uric acid and ascorbic acid). Moreover, a detection range (100 ng/ $\mathrm{mL}-100 \mu \mathrm{g} / \mathrm{mL}$ ) of PfHRP2 concentrations was obtained, which encompassed the clinically relevant level of $P$. falciparum infection. This immunoassay offered a label-free and real-time method for proteins electrochemical detection in biomedical applications.

Urea content in biological urine is an important index in clinical diagnosis. A biosensor based on oxazine 170 perchlorate (O17)-ethyl cellulose (EC) membrane immobilized urease was prepared by Jong Il Rhee for ratiometric fluorescent detection of urea (Dinh Duong and Il Rhee 2015). Under the catalysis of the urease, urea will hydrolyze to produce ammonia, which can react with $\mathrm{O} 17$ to cause the change of two fluorescence emission intensities $\left(\lambda_{\mathrm{em}}=630 \mathrm{~nm}\right.$ and $\lambda_{\mathrm{em}}=565 \mathrm{~nm}$ ). According to a linear relationship between the ratio $\mathrm{I}_{565} / \mathrm{I}_{630}$ of the fluorescence intensities and urea concentrations, a detection range 0.01-0.1 M with LOD of $0.027 \mathrm{mM}$ and a detection range $0.1-1.0 \mathrm{M}$ with LOD of $0.224 \mathrm{mM}$ were obtained. Moreover, after 266 tests in two months, the membrane biosensor still had a good sensitivity, which suggested that this membrane had long-term stability. The biosensor supplied a potential method for urea-sensing in food safety and clinical diagnostics. Similarly, a ratiometric fluorescent biosensor for L-arginine (Arg) and L-asparagine (Asn) detection was designed by Jong Il Rhee, which was combined oxazine 170 perchlorate (O17)-ethyl cellulose (EC) membrane with enzymes and hydrogel polyurethane (An et al. 2017). Ammonium ions were produced by the hydrolysis reactions of urea and L-Arg under the catalysis of the urease and arginase, as well as the hydrolysis reaction of L-Asn under the catalysis of asparaginase. Ammonium ions can react with O17, which led to the ratio $\mathrm{I}_{565} / \mathrm{I}_{630}$ change of the fluorescence intensities, and its proportional to L-Arg and L-Asn concentrations. A concentration range (0.1-10 mM) of L-Arg or L-Asn detection was achieved. The development of this biosensor offered a simple and sensitive method for L-Arg and L-Asn determination in biological fluids, drugs and foods.

Enantiomers of chiral substances are very important in drug discovery and pharmaceutical industry, thus it is urgent to develop a simple, rapid and sensitive method for detecting of chiral molecules. Erhan Zor and co-workers reported a lab-in-a-syringe (LIS) device for colorimetric enantioselective of chiral species sensing, which was consisted of AuNPsloaded cellulose acetate membrane (CAM) as the conjugate pad and non-loaded CAM as detection pad (Zor and Bekar 2017). The conjugate pad was used to capture analytes, which can be recognized by the detection pad and signalled for the captured analytes. Aggregation of AuNPs was caused by the enantioselective interaction between the inherently chiral AuNPs and enantiomers, and subsequently led to a distinct colour change from red to purple within $5 \mathrm{~min}$. There existed a linear equation between colour intensity and L-Alanine concentrations (1-5 mM), with LOD of $0.77 \mathrm{mM}$. On the contrary, D-Alanine did not cause color changes and was not selectively detected. This lab-in-a-syringe (LIS) device paved a novel enantiosensing way for chiral molecules in biomedical fields and pharmaceutical industry.

\section{Pathogen sensors}

Due to environmental changes, species diversity and large-scale use of antibiotics, various pathogens caused the breaking out of infectious diseases, such as Ebola virus, avian influenza virus, swine influenza virus and COVID-19. The traditional pathogen detection methods have the disadvantages of complex experimental operation, high requirements for environment and personnel, which are difficult to meet the needs of rapid detection of pathogens.

When analytes are adsorbed on the substrate surface, Surface enhanced Raman scattering (SERS) can generate enhanced Raman signals, which can be used as biosensors (Pieczonka and Aroca 2008). Vladimir V. Tsukruk and co-workers reported a novel SERS substrate based on cellulose nanofibers (CNFs) membrane and gold nanorods (AuNRs) via direct vacuum-assisted filtration method for simultaneous detection of Escherichia coli and rhodamine 6G (R6G) (Zhang et al. 2018). The nanoporous morphology of CNFs matrix was contributed to the filtration, retention and preconcentration of analytes for 
enhancing SERS performance. Besides, the plasmonic CNFs membranes had various excellent optical properties, including high transmission in the vis-NIR range, low scattering, almost no fluorescence and Raman background, which were applicable to the SERS detection. More interesting, the AuNR/CNF membrane can realize dual operational modes at two excitation wavelengths (532 $\mathrm{nm}$ and $785 \mathrm{~nm}$ ). When the longer excitation wavelength was at $785 \mathrm{~nm}$, the AuNR/CNF membrane displayed autofluorescence suppression for better detecting Escherichia coli with only 100-200 s integration time instead of hours of traditional Raman required. A better Raman scattering efficiency was generated by the shorter excitation wavelength $(532 \mathrm{~nm})$ to recognize R6G dyes, with a detection limit down to $10 \mathrm{pM}$. Although this SERS approach provided sensitive and fast performances, it required a Raman spectrometer.

Pathogenic Escherichia coli O157:H7 is related to bloody diarrhea, abdominal cramps, hemolytic uremic syndrome, renal failure and even death (Richard and Laura 2005). One of the most commonly immunological methods for detecting pathogens is the sandwich ELISA (enzyme-linked immunosorbent assay). A novel chitosan/cellulose nanocrystals/glycerol membrane immobilized monoclonal anti-Shiga toxin $2 \mathrm{~B}$ antibody (mAnti-stx2B-Ab) with the indirect ELISA method was developed by Monique Lacroix and coworkers, for simple and sensitive detection of Escherichia coli O157:H7 (Shankar et al. 2020). A combination of the high specific surface area of the CNCs and functional amino units of the chitosan can result in the increase of antibodies immobilization on membrane surface. Besides, glycerol can not only be served as the membrane stabilizer, but also improved the flexibility of the membranes. The results showed that $\mathrm{CNCs}$ concentrations and chitosan parameters of higher molecular weight, deacetylation degree and viscosity had an important impact on the signal of detection. A detection limit $1 \log \mathrm{CFU} / \mathrm{mL}$ of Escherichia coli O157:H7 was obtained by this immunological membrane. However, compared with the traditional methods of $24 \mathrm{~h}$, the needed time of Escherichia coli $\mathrm{O} 157: \mathrm{H} 7$ detection by this novel method was only $4 \mathrm{~h}$. Monique Lacroix reported a novel spider web trap approach (SWTA) for simultaneous enrichment, capture and detection of Escherichia coli $\mathrm{O} 157: \mathrm{H} 7$ by indirect ELISA method, which was based on chitosan/cellulose nanocrystals/glycerol nanocomposite membrane (Baraketi et al. 2020). The introduction of $\mathrm{CNCs}$ into this nanocomposite membrane can improve the capture of the protein and the detection signal of the pathogen. Moreover, compared with traditional methods, the innovative SWTA did not need any sample preparation, which could minimize the risks of cross-contamination. The development of this CNC-based membrane with indirect ELISA method offered a convenient and sensitive strategy for Escherichia coli O157:H7 detection in food industries and drinking waters.

As an in vitro diagnostic technique, Lateral flow assays (LFAs) can be widely used in disease diagnosis, food detection and environment monitoring because of their low-cost, convenient, portable and efficient, etc. (Geertruida et al. 2009). Quantum dots (QDs) and graphene oxide (GO) exhibited excellent photo-physical properties, which had been intensely applied in biosensing areas (Park et al. 2017; Morales-Narvaez and Merkoci 2019). A lateral flow immunoassay for highly sensitive detection of Escherichia coli O157:H7 was developed by Arben Merkoçi and coworkers, with QDs printing on nitrocellulose membrane substrate as control line and antibody-decorated QDs on the same substrate as test line (Narváez et al. 2015). Upon excitation, when there was no pathogen, the fluorescence of the control line and test line was quenched by a GO flow. However, when the test line selectively captured the pathogens, it did not be significantly quenched compared to the control line (Fig. 9a). The quenching ratio $\mathrm{Q}_{\mathrm{TL}} / \mathrm{Q}_{\mathrm{CL}}$ of the test line and control line determined the selectivity and sensitivity of this lateral flow immunoassay. This sensitive of this detection method for Escherichia coli $\mathrm{O} 157: \mathrm{H} 7$ was clearly observed to $10 \mathrm{CFU} / \mathrm{mL}$ in standard buffer and $100 \mathrm{CFU} / \mathrm{mL}$ in bottled water and milk, respectively. However, the performance of this lateral flow test was affected by the changes of the sample matrix and microenvironments, such as polarity, viscosity, $\mathrm{pH}$ and ionic strength, etc. Staphylococcus aureus, as a common clinical pathogen, can cause skin purulent infection, pneumonia, pericarditis, sepsis and other diseases (Tong et al. 2015). Our group reported the lateral flow assays based on nitrocellulose membranes with cellulose nanofibers for the determination of Staphylococcus aureus (Tang et al. 2019) (Fig. 9b-d). The results showed that the incorporation of cellulose nanofibers into nitrocellulose membranes could improve the adsorption capacity of biomolecules on 


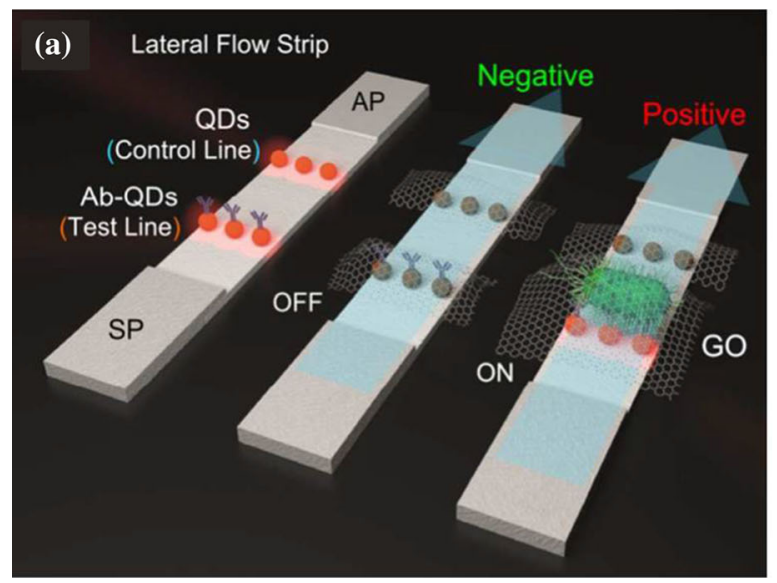

Fig. 9 a Schematic representation of photoluminescent lateral flow test revealed by grapheme oxide (GO) for pathogen detection. Adapted with permission from Narváez et al. (2015), Copyright 2015, American Chemical Society. Schematic illustration of LFAs test strip modified with CNFs. b The

membrane substrate, which was related to the changes of the pore size, porosity, surface groups and surface area of these membranes. According to the changes of the color signal of test line, a detection limit $0.05 \mathrm{nM}$ of cellulose nanofibers-modified LFAs was considerably lower than that of unmodified LFAs at $1 \mathrm{nM}$, which indicated that the sensitivity of this modifiedLFAs for Staphylococcus aureus detection could be increased 20 -fold by adding cellulose nanofibers into the original nitrocellulose membranes. These LFAs provided fast, low-cost, easy to operate and sensitive techniques for pathogen detection in disease diagnosis, food safety and environmental monitoring.

\section{Conclusions}

In this article, we reviewed the preparations of cellulose membranes and their latest developments in the fields of pressure/strain, temperature, humidity, metal cations, non-metal ions, $\mathrm{pH}$, gas/vapor, toxic organic compounds, biomolecules, pathogens and other sensing applications. Combining metal nanowires, metal nanoparticles, graphene oxide/reduced graphene oxide, carbon dots, quantum dots, carbon nanotubes, fluorophores, organic dyes and antigenantibodies with cellulose membranes via physical and chemical bonding can show excellent sensing performances, which indicate that cellulose membranes have

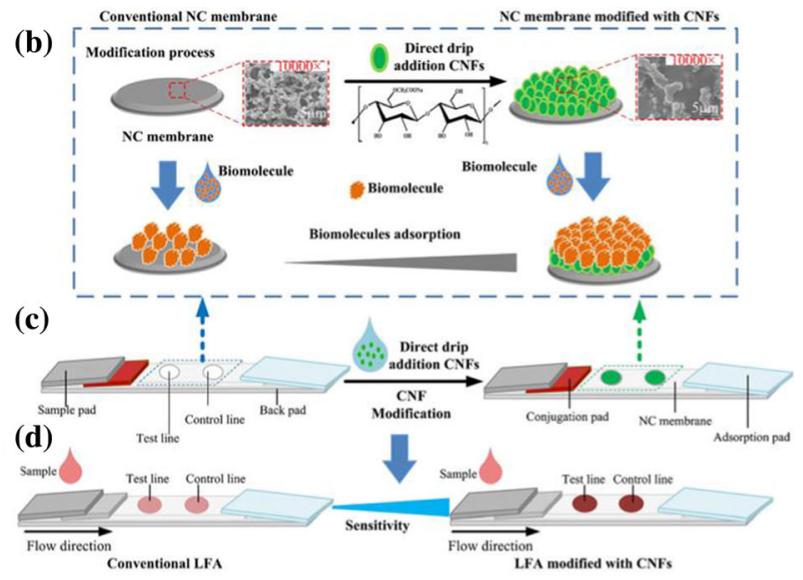

structure illustration of LFAs test strips before and after CNFs modification; c The modification process of CNFs on NC membrane; d Schematic illustration of LFAs test strip detection. Adapted with permission from Tang et al. (2019), Copyright 2019, Springer

great momentums and broad application prospects in the sensing fields. However, there are still some problems: (1) Inherent technical bottlenecks of detection selectivity, sensitivity, response time and reversibility in the sensing fields are still existed. (2) The long-term stability of cellulose membranes in harsh environments (e.g. strong acid, strong alkali, strong solvent, high temperature, high pressure, high ionic strength) still needs to be considered. (3) Cellulose membrane-based sensors for achieving multi-functional simultaneously detection had rarely been reported. (4) The sensing response mechanisms of cellulose membranes are still unclear. And based on the theoretical design, the relationship between the structures and properties of cellulose membranes should be explored. (5) Although a large number of cellulose sensing membranes have been developed, few of them can be commercialized. In addition, low cost, recyclable, portable, biocompatible, miniaturized, integrated and intelligent properties for future practical applications need greater improvement. Moreover, more new applications of cellulose sensing membranes in other fields and interdisciplinary fields should also be explored. With continuous efforts to face these challenges of cellulose membrane-based sensors, we firmly believe that although the road ahead is tortuous, the future is bright.

Acknowledgments The authors thank the Key scientific research plan (Key Laboratory) of Shaanxi Provincial 
Education Department (No. 17JS016), and the International Joint Research Center for biomass chemistry and materials, Shaanxi international science and technology cooperation base (2018GHJD-19), and Shaanxi Key industry innovation chain projects (2020ZDLGY11-03), and Science and Technology Plan of Weiyang District of Xi'an (201910) for financial support.

\section{References}

Amin AS (2015) Application of a triacetylcellulose membrane with immobilizated of 5-(2',4'-dimethylphenylazo)-6-hydroxypyrimidine-2,4-dione for mercury determination in real samples. Sens Actuators B 221:1342-1347. https://doi. org/10.1016/j.snb.2015.07.106

Amin AS, Ahmed IS (2010) Complexation and spectrophotometric study of samarium(III) using pyrimidine Azo derivatives in the presence of cetyltrimethyl ammonium bromide. Anal Lett 43:2598-2608. https://doi.org/10.1080/ 00032711003726910

An K, Duong HD, Rhee JI (2017) Ratiometricfluorescent Larginine and L-asparagine biosensors based on theoxazine 170 perchlorate-ethyl cellulose membrane. Eng Life Sci 17:847-856. https://doi.org/10.1002/elsc.201700033

Angst U, Elsener B, Larsen CK, Vennesland Ø (2009) Critical chloride content in reinforced concrete-a review. Cem Concr Res 39:1122-1138. https://doi.org/10.1016/j. cemconres.2009.08.006

Auerbach SS, Bristol DW, Peckham JC, Travlos GS, Hebert CD, Chhabra RS (2010) Toxicity and carcinogenicity studies of methylene blue trihydrate in $\mathrm{F} 344 \mathrm{~N}$ rats and B6C3F1 mice. Food Chem Toxicol 48:169-177. https:// doi.org/10.1016/j.fct.2009.09.034

Bakirci GT, Yaman Acay DB, Bakirci F, Otles S (2014) Pesticide residues in fruits and vegetables from the Aegean region, Turkey. Food Chem 160:379-392. https://doi.org/ 10.1016/j.foodchem.2014.02.051

Balasubramani V (2020) Review-recentadvances in electrochemical impedance spectroscopy based toxic gas sensorsusing semiconducting metal oxides. J Electrochem Soc 167:037572. https://doi.org/10.1149/1945-7111/ab77a0

Baraketi A, D'Auria S, Shankar S, Fraschini C, Salmieri S, Menissier J, Lacroix M (2020) Novel spider web trap approach based on chitosan/cellulose nanocrystals/glycerol membrane for the detection of Escherichia coli O157:H7 on food surfaces. Int $\mathrm{J}$ Biol Macromol 146:1009-1014. https://doi.org/10.1016/j.ijbiomac.2019. 09.225

Bassyouni M, Abdel-Aziz MH, Zoromba MS, Abdel-Hamid SMS, Drioli E (2019) A review of polymeric nanocomposite membranes for water purification. J Ind Eng Chem 73:19-46. https://doi.org/10.1016/j.jiec.2019.01.045

Bethke $\mathrm{K}$ et al (2018) Functionalized cellulose for water purification, antimicrobial applications, and sensors. Adv Funct Mater 28:1800409. https://doi.org/10.1002/adfm. 201800409

Bhat M, Pandey A (2018) Estimationof $\mathrm{NO}_{2}, \mathrm{SO}_{2}$ and its impact on respiratory human health. Res J Chem Environ Sci 6:90-98
Blank TA, Eksperiandova LP, Belikov KN (2016) Recent trends of ceramic humidity sensors development: a review. Sens Actuators B 228:416-442. https://doi.org/10.1016/j.snb. 2016.01.015

Boyes WK, Degn LL, Martin SA, Lyke DF, Hamm CW, Herr DW (2014) Neurophysiological assessment of auditory, peripheral nerve, somatosensory, and visual system functions after developmental exposure to ethanol vapors. Neurotoxicol Teratol 43:1-10. https://doi.org/10.1016/j. ntt.2014.02.006

Chamkouri N (2015) Development of long-term optical pH sensor using phenol red based on triacetylcellulose membranes. Int J Pharm Technol 7:9096-9104

Chee GJ (2011) Biodegradation analyses of trichloroethylene (TCE) by bacteria and its use for biosensing of TCE. Talanta 85:1778-1782. https://doi.org/10.1016/j.talanta. 2011.07.002

Chee GJ (2016) A novel whole-cell biosensor for the determination of trichloroethylene. Sens Actuators B 237:836-840. https://doi.org/10.1016/j.snb.2016.07.034

Chu CY, Tung L, Lin CY (2013) Effect of substrate concentration and $\mathrm{pH}$ on biohydrogen production kinetics from food industry wastewater by mixed culture. Int J Hydrog Energy 38:15849-15855. https://doi.org/10.1016/j. ijhydene.2013.07.088

Dai L, Wang Y, Zou X, Chen Z, Liu H, Ni Y (2020) Ultrasensitive physical, bio, and chemical sensors derived from 1-, 2-, and 3-D nanocellulosic materials. Small 16:1906567. https://doi.org/10.1002/smll.201906567

Dinh Duong H, Il Rhee J (2015) Development of a ratiometric fluorescent urea biosensor based on the urease immobilized onto the oxazine 170 perchlorate-ethyl cellulose membrane. Talanta 134:333-339. https://doi.org/10.1016/j. talanta.2014.10.064

Douglass EF, Avci H, Boy R, Rojas OJ, Kotek R (2017) Areview of cellulose and cellulose blends for preparation of bio-derived andconventional membranes, nanostructured thin films, and composites. Polym Rev 58:102-163. https:// doi.org/10.1080/15583724.2016.1269124

Duong HD, Kim HL, Rhee JI (2018) Development of colorimetric and ratiometric fluorescence membranes for detection of nitrate in the presence of aluminum-containing compounds. Sensors. https://doi.org/10.3390/s18092883

Dutta G, Lillehoj PB (2018) Wash-free, label-free immunoassay for rapid electrochemical detection of PfHRP2 in whole blood samples. Sci Rep 8:17129. https://doi.org/10.1038/ s41598-018-35471-8

Elmizadeh H, Soleimani M, Faridbod F, Bardajee GR (2017) Ligand-capped CdTe quantum dots as a fluorescent nanosensor for detection of copper ions in environmental water sample. J Fluoresc 27:2323-2333. https://doi.org/10. 1007/s10895-017-2174-3

Fan J, Zhang S, Li F, Shi J (2020a) Cellulose-based sensors for metal ions detection. Cellulose. https://doi.org/10.1007/ s10570-020-03158-X

Fan J, Zhang S, Xu Y, Wei N, Wan B, Qian L, Liu Y (2020b) Apolyethylenimine/salicylaldehyde modified cellulose Schiff base for selectiveand sensitive $\mathrm{Fe}^{3+}$ detection. Carbohydr Polym 228:115379. https://doi.org/10.1016/j. carbpol.2019.115379 
Feng X, Wang K, Mu Z, Zhao Y, Zhang H (2015) Fluazinamresidue and dissipation in potato tubers and vines, and in field soil. Am J Potato Res 92:567-572. https://doi.org/10. 1007/s12230-015-9469-1

Fu W et al (2019) Electronic textiles based on aligned electrospun belt-like cellulose acetate nanofibers and graphene sheets: portable, scalable and eco-friendly strain sensor. Nanotechnology 30:045602. https://doi.org/10.1088/13616528/aaed99

Geertruida A, Posthuma T, Jakob K, Aart A (2009) Lateral flow (immuno) assay: its strengths, weaknesses, opportunities and threats. A literature survey. Anal Bioanal Chem 393:569-582. https://doi.org/10.1007/s00216-008-2287-2

Gentili D et al (2018) Integration of organic electrochemical transistors and immuno-affinity membranes for label-free detection of interleukin- 6 in the physiological concentration range through antibody-antigen recognition. J Mater Chem B 6:5400-5406. https://doi.org/10.1039/c8tb01697f

Ghoneim MT, Nguyen A, Dereje N, Huang J, Moore GC, Murzynowski PJ, Dagdeviren C (2019) Recentprogress in electrochemical $\mathrm{pH}$-sensing materials and configurations forbiomedical applications. Chem Rev 119:5248-5297. https://doi.org/10.1021/acs.chemrev.8b00655

Gotor R, Ashokkumar P, Hecht M, Keil K, Rurack K (2017) OpticalpH sensor covering the range from $\mathrm{pH}$ 0-14 compatible with mobile-device readoutand based on a set of rationally designed indicator dyes. Anal Chem 89:8437-8444. https://doi.org/10.1021/acs.analchem. $7 \mathrm{~b} 01903$

Gu Y, Wang M, Li G (2017) CNTs-anchoredcellulose fluorescent nanofiber membranes as fluorescence sensor for $\mathrm{Cu}^{2+}$ and $\mathrm{Cr}^{3+}$. Anal Methods 9:6044-6048. https://doi. org/10.1039/C7AY01994G

Hao J, Han MJ, Meng X (2009) Preparation and evaluation of thiol-functionalized activated alumina for arsenite removal from water. J Hazard Mater 167:1215-1221. https://doi. org/10.1016/j.jhazmat.2009.01.124

Hassan AF, Abdel-Mohsen AM, Fouda MM (2014) Comparative study of calcium alginate, activated carbon, and their composite beads on methylene blue adsorption. Carbohydr Polym 102:192-198. https://doi.org/10.1016/j.carbpol. 2013.10.104

He S, Fang H, Xu X (2016) Filtering absorption and visual detection of methylene blue by nitrated cellulose acetate membrane. Korean J Chem Eng 33:1472-1479. https://doi. org/10.1007/s11814-015-0231-7

He K, Zhan X, Liu L, Ruan X, Wu Y (2020) Ratiometricfluorescent paper-based sensor based on CdTe quantum dots and graphite carbonnitride hybrid for visual and rapid determination of $\mathrm{Cu}^{(2+)}$ in drinks. Photochem Photobiol. https://doi.org/10.1111/php.13271

Hendriksen IC et al (2013) Defining falciparum-malaria-attributable severe febrile illness in moderate-to-high transmission settings on the basis of plasma PfHRP2 concentration. J Infect Dis 207:351-361. https://doi.org/ 10.1093/infdis/jis675

Hittini W, Abu-Hani AF, Reddy N, Mahmoud ST (2020) Cellulose-copper oxide hybrid nanocomposites membranes for $\mathrm{H} 2 \mathrm{~S}$ gas detection at low temperatures. Sci Rep 10:2940. https://doi.org/10.1038/s41598-020-60069-4
Jamroz E, Kocot K, Zawisza B, Talik E, Gagor A, Sitko R (2019) A green analytical method for ultratrace determination of hexavalent chromium ions based on micro-solid phase extraction using amino-silanized cellulose membranes. Microchem J 149:104060. https://doi.org/10.1016/ j.microc.2019.104060

Jheng LC, Hsiao CH, Ko WC, Hsu SL, Huang YL (2019) Conductive films based on sandwich structures of carbon nanotubes/silver nanowires for stretchable interconnects. Nanotechnology 30:235201. https://doi.org/10.1088/13616528/ab0483

Jiang X, Xia J, Luo X (2020a) Simple,rapid, and highly sensitive colorimetric sensor strips from a porous cellulosemembrane stained with Victoria blue B for efficient detection of trace Cd(II)in water. ACS Sustain Chem Eng 8:5184-5191. https://doi.org/10.1021/acssuschemeng.9b07614

Jiang $\mathrm{Y}$ et al (2020b) Preparation of dual-emission polyurethane/carbon dots thermoresponsive composite films for colorimetric temperature sensing. Carbon 163:26-33. https://doi.org/10.1016/j.carbon.2020.03.013

Khullar S, Singh S, Das P, Mandal SK (2019) Luminescent lanthanide-based probes for the detection of nitroaromatic compounds in water. ACS Omega 4:5283-5292. https:// doi.org/10.1021/acsomega.9b00223

Kim T, Bao C, Hausmann M, Siqueira G, Zimmermann T, Kim WS (2019) 3D printeddisposable wireless ion sensors with biocompatible cellulose composites. Adv Electron Mater 5:1800778. https://doi.org/10.1002/aelm.201800778

Koch M, Bowes G, Ross C, Zhang XH (2013) Climate change and ocean acidification effects on seagrasses and marine macroalgae. Glob Change Biol 19:103-132. https://doi. org/10.1111/j.1365-2486.2012.02791.x

Kulkarni PS, Ramekar PV, Kulkarni SD (2018) An optical sensor for selenite determination in aqueous samples. J Anal Sci Technol. https://doi.org/10.1186/s40543-0180136-2

Lee WJ, Bao Y, Hu X, Lim T-T (2019) Hybridcatalytic ozonation-membrane filtration process with $\mathrm{CeO}_{x}$ and $\mathrm{MnO}_{\mathrm{x}}$ impregnated catalytic ceramic membranes for micropollutants degradation. Chem Eng J 378:121670. https://doi.org/10.1016/j.cej.2019.05.031

Li J et al (2017a) Detection of trace nickel ions with a colorimetric sensor based on indicator displacement mechanism. Sens Actuators B 241:1294-1302. https://doi.org/10.1016/ j.snb.2016.09.191

Li J, Wang X, Huo D, Hou C, Fa H, Yang M, Zhang L (2017b) Colorimetricmeasurement of $\mathrm{Fe}^{3+}$ using a functional paper-based sensor based oncatalytic oxidation of gold nanoparticles. Sens Actuators B 242:1265-1271. https:// doi.org/10.1016/j.snb.2016.09.039

Li N et al (2017c) Facilesynthesis of cellulose acetate ultrafiltration membrane withstimuli-responsiveness to $\mathrm{pH}$ and temperature using the additive of F127-b-PDMAEMA. Chin J Chem 35:1109-1116. https://doi.org/10.1002/cjoc. 201600820

Li M et al (2018) Fluorescence detection and removal of copper from water using a biobased and biodegradable 2D soft material. Chem Commun 54:184-187. https://doi.org/10. 1039/c7cc08035b

Liao C, Mak C, Zhang M, Chan HL, Yan F (2015) Flexible organic electrochemical transistors for highly selective 
enzyme biosensors and used for saliva testing. Adv Mater 27:676-681. https://doi.org/10.1002/adma.201404378

Lin P, Yan F (2012) Organic thin-film transistors for chemical and biological sensing. Adv Mater 24:34-51. https://doi. org/10.1002/adma.201103334

Liu G, Qi M, Hutchinson MR, Yang G, Goldys EM (2016) Recent advances in cytokine detection by immunosensing. Biosens Bioelectron 79:810-821. https://doi.org/10.1016/j. bios.2016.01.020

Liu j et al (2020) Naphthalimide-containing coordination polymer with mechanoresponsive luminescence and excellent metal ion sensing properties. Dalton Trans 49:3174-3180. https://doi.org/10.1039/C9DT04928B

Lochbaum A et al (2020) Compact mid-infrared gas sensing enabled by an all-metamaterial design. Nano Lett. https:// doi.org/10.1021/acs.nanolett.0c00483

Lou M, Abdalla I, Zhu M, Yu J, Li Z, Ding B (2020) Hierarchicallyrough structured and self-powered pressure sensor textile for motion sensingand pulse monitoring. ACS Appl Mater Interfaces 12:1597-1605. https://doi.org/10.1021/ acsami.9b19238

Lu Z, Chen X, Hu W (2017) A fluorescence aptasensor based on semiconductor quantum dots and MoS2 nanosheets for ochratoxin A detection. Sens Actuators B 246:61-67. https://doi.org/10.1016/j.snb.2017.02.062

Lukojko E, Talik E, Gagor A, Sitko R (2018) Highly selective determination of ultratrace inorganic arsenic species using novel functionalized miniaturized membranes. Ana Chim Acta 1008:57-65. https://doi.org/10.1016/j.aca.2017.12. 038

Luo X, Xia J, Jiang X, Yang M, Liu S (2019) Cellulosebasedstrips designed based on a sensitive enzyme colorimetric assay for the lowconcentration of glucose detection. Anal Chem 91:15461-15468. https://doi.org/10.1021/acs. analchem.9b03180

Lv C et al (2019a) Recent advances in graphene-based humidity sensors. Nanomaterials. https://doi.org/10.3390/ nano9030422

Lv P et al (2019b) In situ 3D bacterial cellulose/nitrogen-doped graphene oxide quantum dot-based membrane fluorescent probes for aggregation-induced detection of iron ions. Cellulose 26:6073-6086. https://doi.org/10.1007/s10570019-02476-z

Masoud N et al (2018) Ventilatory disorders associated with occupational inhalation exposure to nitrogen trihydride (ammonia). Ind Health 56:427-435

Mautner A (2020) Nanocellulose water treatment membranes and filters: a review. Polym Int. https://doi.org/10.1002/pi. 5993

Mazza MMA, Raymo FM (2019) Structural designs for ratiometric temperature sensing with organic fluorophores. J Mater Chem C 7:5333-5342. https://doi.org/10.1039/ c9tc00993k

Mehta P, Vedachalam S, Sathyaraj G, Garai S, Arthanareeswaran G, Sankaranarayanan K (2020) Fast sensing ammonia at room temperature with proline ionic liquid incorporated cellulose acetate membranes. J Mol Liq 305:112820. https://doi.org/10.1016/j.molliq.2020.112820

Morales-Narvaez E, Merkoci A (2019) Grapheneoxide as an optical biosensing platform: a progress report. Adv Mater 31:1805043. https://doi.org/10.1002/adma.201805043
Narváez E, Naghdi T, Zor E, Merkoçi A (2015) Photoluminescentlateral-flow immunoassay revealed by graphene oxide: highly sensitivepaper-based pathogen detection. Anal Chem 87:8573-8577. https://doi.org/10.1021/acs. analchem.5b02383

Núñez-Carmona E, Bertuna A, Abbatangelo M, Sberveglieri V, Comini E, Sberveglieri G (2019) BC-MOS: the novel bacterial cellulose based MOS gas sensors. Mater Lett 237:69-71. https://doi.org/10.1016/j.matlet.2018.11.011

Ning Y, Zhu M, Zhang J-L (2019) Near-infrared (NIR) lanthanide molecular probes for bioimaging and biosensing. Coord Chem Rev 399:213028. https://doi.org/10.1016/j. ccr.2019.213028

Park M, Seo TS (2019) An integrated microfluidic device with solid-phase extraction and graphene oxide quantum dot array for highly sensitive and multiplex detection of trace metal ions. Biosens Bioelectron 126:405-411. https://doi. org/10.1016/j.bios.2018.11.010

Park Y, Jeong S, Kim S (2017) Medically translatable quantum dots for biosensing and imaging. J Photochem Photobiol C 30:51-70. https://doi.org/10.1016/j.jphotochemrev.2017. 01.002

Pieczonka NP, Aroca RF (2008) Single molecule analysis by surfaced-enhanced Raman scattering. Chem Soc Rev 37:946-954. https://doi.org/10.1039/b709739p

Qi HJ, Chen SH, Zhang ML, Shi H, Wang SQ (2010) DNA microarrays for visual detection of human pathogenic microorganisms based on tyramine signal amplification coupled with gold label silver stain. Anal Bioanal Chem 398:2745-2750. https://doi.org/10.1007/s00216-0104189-3

Rao A, Kumar GS, Roy S, Rajesh AT, Devatha G, Pillai PP (2019) Turn-onselectivity in inherently nonselective gold nanoparticles for $\mathrm{Pb}^{2+}$ detectionby preferential breaking of interparticle interactions. ACS Appl Nano Mater 2:5625-5633. https://doi.org/10.1021/acsanm.9b01168

Regev N, Wulich D (2019) Remote sensing of vital signs using an ultra-wide-band radar. Int $J$ Remote Sens 40:6596-6606. https://doi.org/10.1080/2150704x.2019. 1573335

Richard L, Laura D (2005) Escherichia coli O157:H7 outbreak associated with consumption ofground beef, June-July 2002. Public Health Rep 120:174-178. https://doi.org/10. $1177 / 003335490512000211$

Sadasivuni KK, Kafy A, Kim H-C, Ko H-U, Mun S, Kim J (2015) Reduced graphene oxide filled cellulose films for flexible temperature sensor application. Synth Met 206:154-161. https://doi.org/10.1016/j.synthmet.2015.05. 018

Shaheen K, Shah Z, Khan B, Adnan, Omer M, Alamzeb M, Suo $\mathrm{H}$ (2020) Electrical, photocatalytic, and humidity sensing applications of mixed metal oxide nanocomposites. ACS Omega 5:7271-7279. https://doi.org/10.1021/acsomega. 9b04074

Shankar S et al (2020) Development of support based on chitosan and cellulose nanocrystals for the immobilization of anti-Shiga toxin 2B antibody. Carbohydr Polym 232:115785. https://doi.org/10.1016/j.carbpol.2019. 115785

Syrový T et al (2019) Wide range humidity sensors printed on biocomposite films of cellulose nanofibril and 
poly(ethylene glycol). J Appl Polym Sci. https://doi.org/10. 1002/APP.47920

Tang J, Xu Z, Zhou L, Qin H, Wang Y, Wang H (2010) Rapidand simultaneous detection of Ureaplasmaparvum and Chlamydia trachomatis antibodies based on visual protein microarrayusing gold nanoparticles and silver enhancement. Diagn Microbiol Infect Dis 67:122-128. https://doi. org/10.1016/j.diagmicrobio.2010.01.009

Tang H, Yan F, Lin P, Xu J, Chan HLW (2011) Highlysensitive glucose biosensors based on organic electrochemical transistors usingplatinum gate electrodes modified with enzyme and nanomaterials. Adv Funct Mater 21:2264-2272. https://doi.org/10.1002/adfm.201002117

Tang RH, Liu LN, Zhang SF, Li A, Li Z (2019) Modificationof a nitrocellulose membrane with cellulose nanofibers for enhanced sensitivityof lateral flow assays: application to the determination of Staphylococcus aureus. Mikrochim Acta 186:831. https://doi.org/10.1007/s00604-019-3970-z

Tanvir N, Yurchenko O, Wilbertz C, Urban G (2016) Investigationof $\mathrm{CO}_{2}$ reaction with copper oxide nanoparticles for room temperaturegas sensing. J Mater Chem A 4:5294-5302. https://doi.org/10.1039/C5TA09089J

Thakur N, Kumar SA, Kumar KSA, Pandey AK, Kumar SD, Reddy AVR (2015) Development of a visual optode sensor for onsite determination of $\mathrm{Hg}(\mathrm{II})$. Sens Actuators B 211:346-353. https://doi.org/10.1016/j.snb.2015.01.087

Thakur VK, Voicu SI (2016) Recent advances in cellulose and chitosan based membranes for water purification: a concise review. Carbohydr Polym 146:148-165. https://doi.org/10. 1016/j.carbpol.2016.03.030

Tong SY, Davis JS, Eichenberger E, Holland TL, Fowler VG Jr (2015) Staphylococcus aureus infections: epidemiology, pathophysiology, clinical manifestations, and management. Clin Microbiol Rev 28:603-661. https://doi.org/10. 1128/CMR.00134-14

Uehara Y, Karami D, Mahinpey N (2019) $\mathrm{CO}_{2}$ adsorption using amino acid ionic liquid-impregnated mesoporous silica sorbentswith different textural properties. Microporous Mesoporous Mater 278:378-386. https://doi.org/10.1016/j. micromeso.2019.01.011

Ventura MG, Stibilj V, Freitas MdC, Pacheco AMG (2009) Determination of ultratrace levels of selenium in fruit and vegetable samples grown and consumed in Portugal. Food Chem 115:200-206. https://doi.org/10.1016/j.foodchem. 2008.10.089

Waleed Al-Qaysi W, Duerkop A (2018) A luminescent europium complex for wide-range $\mathrm{pH}$ sensors and sensor microtiterplates. Analyst 143:3176-3183. https://doi.org/ 10.1039/c8an00775f

Wang CY, Fang BY, Yao MH, Zhao YD (2016a) Visualization detection of ultratrace lead and cadmium ions using cellulose acetate membrane based on silver stain. Sens Actuators B 228:643-648. https://doi.org/10.1016/ j.snb.2016a.01.080

Wang X, Li J-H, Li Y-L, Liu L-J, Guan W-M (2016b) Emulsiontemplated fully three-dimensional interconnected porous titania ceramics with excellent humidity sensing properties. Sens Actuators B 237:894-898. https://doi.org/10. 1016/j.snb.2016.07.014

Wang X, Wu Q, Jiang K, Wang C, Zhang C (2017) One-step synthesis of water-soluble and highly fluorescent MoS2 quantum dots for detection of hydrogen peroxide and glucose. Sens Actuators B 252:183-190. https://doi.org/10. 1016/j.snb.2017.05.177

Wang J et al (2020a) Stabilizedzirconia-based solid state electrochemical gas sensor coupled with $\mathrm{CdTiO}_{3}$ for acetylene detection. Sens Actuators B 316:128199. https://doi.org/ 10.1016/j.snb.2020.128199

Wang X et al (2020b) MoS2 QDs-based sensor for measurement of fluazinam with triple signal output. Anal Chim Acta 1108:152-159. https://doi.org/10.1016/j.aca.2020.02.028

Weishaupt R et al (2020) Antibacterial,cytocompatible, sustainably sourced: cellulose membranes with bifunctionalpeptides for advanced wound dressings. Adv Healthc Mater 9:1901850. https://doi.org/10.1002/adhm. 201901850

Xiao W, Ding L, He J, Huang J (2019) Preparation of lucigenindoped silica nanoparticles and their application in fiber optic chloride ion sensor. Opt Mater 98:109467. https://doi. org/10.1016/j.optmat.2019.109467

Yang C, Veiga C, Rodriguez-Andina JJ, Farina J, Iniguez A, Yin S (2019) UsingPPG signals and wearable devices for atrial fibrillation screening. IEEE Trans Ind Electron 66:8832-8842. https://doi.org/10.1109/tie.2018.2889614

Ye X, Kang Y, Zhou J (2020) Rhodaminelabeled cellulose nanocrystals as selective "naked-eye" colorimetric andfluorescence sensor for $\mathrm{Hg}^{2+}$ in aqueous solutions. Cellulose. https://doi.org/10.1007/s10570-020-03126-5

Zhang J, Zhou L (2018) Preparation and optimization of optical pH sensor based on sol-gel. Sensors. https://doi.org/10. 3390/s18103195

Zhang J et al (2017) Greensolid electrolyte with cofunctionalized nanocellulose/graphene oxideinterpenetrating network for electrochemical gas sensors. Small Methods 1:1700237. https://doi.org/10.1002/smtd.201700237

Zhang S, Xiong R, Mahmoud MA, Quigley EN, Chang H, ElSayed M, Tsukruk VV (2018) Dual-excitation nanocellulose plasmonic membranes for molecular and cellular SERS detection. ACS Appl Mater Interfaces 10:18380-18389. https://doi.org/10.1021/acsami.8b04817

Zhang H, Sun X, Hubbe MA, Pal L (2019a) Highly conductive carbon nanotubes and flexible cellulose nanofibers composite membranes with semi-interpenetrating networks structure. Carbohydr Polym 222:115013. https://doi.org/ 10.1016/j.carbpol.2019.115013

Zhang H, Zhao S, Wang X, Ren X, Ye J, Huang L, Xu S (2019b) Theenhanced photoluminescence and temperature sensing performance in rare earthdoped $\mathrm{SrMoO}_{4}$ phosphors by aliovalent doping: from material design todevice applications. J Mater Chem C 7:15007-15013. https://doi.org/10. $1039 / \mathrm{c} 9 \mathrm{tc} 04965 \mathrm{~g}$

Zhang L et al (2019c) Dual-emittingfilm with cellulose nanocrystal-assisted carbon dots grafted $\mathrm{SrAl}_{2} \mathrm{O}_{4}, \mathrm{Eu}^{(2+)}$, $\mathrm{Dy}^{(3+)}$ phosphors for temperature sensing. Carbohydr Polym 206:767-777. https://doi.org/10.1016/j.carbpol. 2018.11.031

Zhang Z, Liu G, Li X, Zhang S, Lu X, Wang Y (2020) Design and synthesis of fluorescent nanocelluloses for sensing and bioimaging applications. ChemPlusChem 85:487-502. https://doi.org/10.1002/cplu.201900746

Zhou T, Yang Y, Zhou K, Jin M, Han M, Li W, Yin C (2019a) Efficiently mitochondrial targeting fluorescent imaging of 
H2S invivo based on a conjugate-lengthened cyanine NIR fluorescent probe. Sens Actuators B 301:127116. https:// doi.org/10.1016/j.snb.2019.127116

Zhu L, Zhou X, Liu Y, Fu Q (2019b) Highlysensitive, ultrastretchable strain sensors prepared by pumping hybrid fillersof carbon nanotubes/cellulose nanocrystal into electrospun polyurethanemembranes. ACS Appl Mater Interfaces 11:12968-12977. https://doi.org/10.1021/acsami. $9 \mathrm{~b} 00136$

Zhu P, Liu Y, Fang Z, Kuang Y, Zhang Y, Peng C, Chen G (2019c) Flexibleand highly sensitive humidity sensor based on cellulose nanofibers and carbonnanotube composite film. Langmuir 35:4834-4842. https://doi.org/ 10.1021/acs.langmuir.8b04259

Zor E, Bekar N (2017) Lab-in-a-syringe using gold nanoparticles for rapid colorimetric chiral discrimination of enantiomers. Biosens Bioelectron 91:211-216. https://doi.org/ 10.1016/j.bios.2016.12.031

Publisher's Note Springer Nature remains neutral with regard to jurisdictional claims in published maps and institutional affiliations. 